\title{
Abrupt Circulation Responses to Tropical Upper-Tropospheric Warming in a Relatively Simple Stratosphere-Resolving AGCM
}

\author{
SHUGUANG WANG \\ Department of Applied Physics and Applied Mathematics, Columbia University, New York, New York \\ EDWIN P. GERBER \\ Center for Atmosphere Ocean Science, Courant Institute of Mathematical Sciences, New York University, New York, New York
}

\section{LORENZO M. POLVANI}

Department of Applied Physics and Applied Mathematics, Department of Earth and Environmental Sciences, Columbia University, New York, New York

(Manuscript received 24 March 2011, in final form 19 December 2011)

\begin{abstract}
The circulation response of the atmosphere to climate change-like thermal forcing is explored with a relatively simple, stratosphere-resolving general circulation model. The model is forced with highly idealized physics, but integrates the primitive equations at resolution comparable to comprehensive climate models. An imposed forcing mimics the warming induced by greenhouse gasses in the low-latitude upper troposphere. The forcing amplitude is progressively increased over a range comparable in magnitude to the warming projected by Intergovernmental Panel on Climate Change coupled climate model scenarios. For weak to moderate warming, the circulation response is remarkably similar to that found in comprehensive models: the Hadley cell widens and weakens, the tropospheric midlatitude jets shift poleward, and the Brewer-Dobson circulation (BDC) increases. However, when the warming of the tropical upper troposphere exceeds a critical threshold, $\sim 5 \mathrm{~K}$, an abrupt change of the atmospheric circulation is observed. In the troposphere the extratropical eddy-driven jet jumps poleward nearly $10^{\circ}$. In the stratosphere the polar vortex intensifies and the BDC weakens as the intraseasonal coupling between the troposphere and the stratosphere shuts down. The key result of this study is that an abrupt climate transition can be effected by changes in atmospheric dynamics alone, without need for the strong nonlinearities typically associated with physical parameterizations. It is verified that the abrupt climate shift reported here is not an artifact of the model's resolution or numerics.
\end{abstract}

\section{Introduction}

Climate models predict that there will be a substantial warming of the earth's atmosphere by the end of the twenty-first century, accompanied by significant changes in the general circulation of the troposphere and stratosphere, if anthropogenic greenhouse gas (GHG) emissions are not abated. Coupled atmosphere-ocean climate models project that the tropospheric extratropical jets will shift poleward (e.g., Yin 2005; Miller et al. 2006),

Corresponding author address: Shuguang Wang, Department of Applied Physics and Applied Mathematics, Columbia University, 500 W. 120th St., New York, NY 10027.

E-mail: sw2526@columbia.edu accompanied by an expansion of the tropical Hadley cells both poleward and upward (e.g., Frierson et al. 2007; Lu et al. 2008). In the stratosphere, chemistry-climate models project an acceleration of the Brewer-Dobson circulation (BDC) (e.g., Butchart et al. 2006; Li et al. 2008; McLandress and Shepherd 2009b) with the potential to substantially change the distribution of ozone by the end of the century (Shepherd 2008). Recent circulation trends in the stratosphere are arguably less certain in the observations (e.g., Engel et al. 2009; Garcia et al. 2011), but small tropospheric trends have already been observed (e.g., $\mathrm{Hu}$ and Fu 2007; Seidel and Randel 2007). Overall, most climate projections suggest a continuation or gentle acceleration of current warming and circulation trends. 
We have learned from studying the earth's climate record, however, that climate change in the past has sometimes been more erratic and abrupt (e.g., Seager and Battisti 2006; Alley 2007; Clement and Peterson 2008). Integrations with highly truncated climate models, so-called Earth System Models of Intermediate Complexity (EMICs), have demonstrated cases when the climate's sensitivity to external forcing changes suddenly (e.g., Ganopolski and Rahmstorf 2001; Claussen et al. 2002; Weber 2010). Such regime transitions have not been as readily observed in most comprehensive climate models, such as those evaluated in the Intergovernmental Panel on Climate Change Fourth Assessment Report (IPCC AR4). It is possible that comprehensive models have been overly constrained to match the recent climate record. On the other hand, the regime behavior found in EMICs could be influenced by their severe truncation; in dynamical systems, increasing the available degrees of freedom often leads to the loss of regimes.

In this study, we investigate the potential for abrupt changes in the atmospheric circulation with a simplified atmospheric general circulation model (AGCM). Complementary to EMICs, which attempt to parameterize all of the important physical processes in the earth system, but poorly represent atmospheric dynamics, our AGCM is forced with highly idealized physics, but its numerical resolution is comparable to, or even exceeds, that of many comprehensive GCMs. While the simplified physics clearly prevents us from independently predicting future climate, it enables us to attribute circulation changes to specific forcings inferred from comprehensive integrations. In this paper, we carefully confirm that many of the circulation changes through the depth of the atmosphere predicted by comprehensive GCMs can be understood as the dynamical response to warming of the tropical upper troposphere, as hinted by Eichelberger and Hartmann (2005) and explored by Butler et al. (2010). More importantly, the simplified nature of our model physics allows us to explore the atmospheric response as a function of the forcing amplitude over a wide range, thereby demonstrating the potential for abrupt climate transitions due to a change in atmospheric circulation regimes. Our results highlight the possibility of abrupt climate change arising out of nonlinear atmospheric dynamics (e.g., Corti et al. 1999), as opposed to the nonlinear climate physics emphasized by EMICs, and we verify that these results are not an artifact of numerical truncation.

Butler et al. (2010) demonstrated that AGCMs with idealized physics can be used to study climate change. Increased GHG loading causes the upper troposphere to warm more than the surface due to the lapse rate feedback, a result of the exponential increase in saturation water vapor pressure with temperature. This temperature dependence also causes the lapse rate feedback to be strongest in the tropics, increasing the meridional temperature gradient in the upper troposphere. As the dry circulation depends primarily on the gradients of temperature, Butler et al. (2010) showed that these effects could be approximated in a dry GCM by prescribing a simple heating in the tropical upper troposphere. They found that the resulting circulation response captured key aspects of the changes found in comprehensive models, including the expansion of the tropics and the poleward shift of the extratropical jets. In the stratosphere, however, the BDC in their model weakens as a result of climate change, in contrast to chemistry-climate model predictions. Another study by Eichelberger and Hartmann (2005) with a similar idealized GCM, but slightly different forcings, found that BDC strengthens in response to tropical warming.

Here we extend and reconcile these results by building upon the model of Gerber and Polvani (2009), a dry primitive equation model on the sphere designed to capture stratosphere-troposphere coupling. We prescribe a tropical heating as in Butler et al. (2010) to mimic climate change, but its strength is systematically varied over a wide range. This procedure reveals an abrupt transition when the tropical warming exceeds a certain threshold; trends in both the troposphere and stratosphere change abruptly, some reversing sign. This abrupt transition is particularly clear in the stratosphere where it leads to substantial weakening of its coupling with the troposphere. Before the transition the BDC strengthens, as in Eichelberger and Hartmann (2005); after the transition, in the warming regime analyzed by Butler et al. (2010), the circulation is much reduced. As the Gerber and Polvani (2009) model captures the coupling between the stratosphere and troposphere on both intraseasonal and climatological time scales, we also probe changes in the internal variability with climate change and find similar abrupt transitions in the unforced variability, such as in the frequency of stratospheric sudden warmings (SSWs).

The paper is organized as follows. We document the model and our methodology in section 2, and then illustrate the reference climatology and the response to tropical warming perturbations in section 3. Section 4 highlights the abrupt transition in the atmospheric circulation precipitated by increased GHG-like induced warming, and section 5 focuses on the response of the stratosphere and its coupling with the troposphere. We discuss the importance of regime behavior to the abrupt climate response in section 6 , and establish the robustness of our results to model numerics and our treatment of gravity wave forcing in section 7. Last, we present our conclusions in section 8 . 


\section{Model and methodology}

The primary atmospheric GCM used in this study integrates the dry primitive equations on the sphere with a pseudospectral numerical scheme. The code was developed by the Geophysical Fluid Dynamics Laboratory (GFDL). It is run with perpetual January conditions, maintained by Newtonian relaxation to a prescribed temperature equilibrium profile, and Rayleigh drag at the surface and upper boundary that approximate surface friction and gravity wave drag, respectively, as described in detail by Polvani and Kushner (2002). Its tropospheric forcing is identical to that proposed by Held and Suarez (1994) except for a factor to introduce interhemispheric asymmetry consistent with the solstice. We focus on the Northern Hemisphere ( $\mathrm{NH}$ ) winter, as this is the period of maximal coupling between the troposphere and stratosphere on intraseasonal time scales. In the reference integration (REF), planetary waves are forced with a simple zonal wavenumber-2 topography of maximum amplitude $3000 \mathrm{~m}$, located between $25^{\circ}$ and $65^{\circ} \mathrm{N}$, and the polar stratospheric vortex temperature is relaxed to a profile with lapse rate $\gamma=4 \mathrm{~K} \mathrm{~km}^{-1}$ to produce realistic stratospheric coupling on intraseasonal time scales. This is the configuration analyzed by Gerber and Polvani (2009, their integration 9) and Gerber et al. (2009) that exhibits the most realistic NH-like variability in terms of the frequency of SSWs and the downward coupling of the northern annular mode (NAM).

To establish the robustness of the results, most integrations are performed at three resolutions. Triangular truncation at wavenumber 42 with $40 \sigma=p / p_{s}$ (where $p$ and $p_{s}$ are pressure and surface pressure, respectively) levels in the vertical, denoted T42L40, is the resolution used most extensively in Gerber and Polvani (2009). The 40 vertical levels are spaced roughly evenly in height with a model top above $1 \mathrm{~Pa}$. The sensitivity to vertical resolution is explored in integrations with 80 levels, T42L80. The levels are chosen with the scheme of Polvani and Kushner (2002) so that T42L80 has 40 levels identical to T42L40, with additional levels spaced in between each, and a comparable model top. In addition, T85L40 integrations were performed with the same vertical levels as T42L40 but twice the horizontal resolution. Our purpose for using different horizontal and vertical resolution is to examine to what extent our numerical results are robust. We do not seek numerical convergence, which is well beyond the scope of this study. For brevity, the three sets of integrations will be referred to as T42, L80, and T85 unless otherwise mentioned.

To approximate the impact of increased GHG concentrations on the atmospheric circulation, we add to the REF configuration a heating centered in the tropical upper troposphere, intended to mimic an enhanced tropical warming. The imposed heating is identical to that in Butler et al. (2010):

$$
H=H_{0} \exp \left\{-\left[\frac{\phi^{2}}{2 \times 0.4^{2}}+\frac{(\sigma-0.3)^{2}}{2 \times 0.11^{2}}\right]\right\},
$$

where $H_{0}$ is the amplitude and $\phi$ is the latitude in radians. The half-width of the forcing is approximately $27^{\circ}$ in latitude. This heating is zonally symmetric, and its shape is illustrated by the shaded area in Fig. 1a. The amplitude of the imposed forcing, $H_{0}$, is the key parameter to be explored in this study; our motivation is to understand to what degree the atmospheric circulation responds linearly to external forcing. We vary $H_{0}$ from -0.1 to $0.5 \mathrm{~K} \mathrm{day}^{-1}$ for integrations with the three different combinations of horizontal and vertical resolutions, as listed in Table 1.

In a moist atmosphere, the warming of the tropical upper troposphere relative to surface and midlatitudes is governed by lapse rate constraints associated with moist convection. Thus, it is important not to view the warming in our dry model as a direct heating induced by GHGs, but rather as a response of a moist atmosphere to GHG-induced surface warming, one that we approximate in our model with an otherwise unphysical heating.

The time scales of the atmospheric circulation, in contrast to the ocean, are short relative to those associated with anthropogenic forcing. We can thus estimate the impact of climate forcing on the circulation in our idealized model by comparing the steady-state responses to various levels of steady heating. All experiments are integrated for 10000 days after 300 days of spin up. Considering that these are perpetual January integrations, these are equivalent to 120 years of winter seasons.

\section{Model climatology and response to tropical warming}

The climatological temperature and zonal wind structure of our T42 REF integration are displayed in Figs. 1a,b. The tropospheric westerly jets are located near $40^{\circ} \mathrm{S}$ and $30^{\circ} \mathrm{N}$ at $300 \mathrm{hPa}$, and the polar night jet in the winter stratosphere is located near $70^{\circ} \mathrm{N}$. The amplitude and location of each are consistent with observations (e.g., Peixoto and Oort 1992). The standard lapse rate tropopause is indicated by the dark line in Fig. 1a. It is relatively low in the tropics, $190 \mathrm{hPa}$, because the model's equilibrium temperature profile was optimized to capture the high-latitude tropopause. In general, the tropical circulation of the model should be analyzed with caution, given the lack of moist processes. 
(a) T, tropopause and forcing

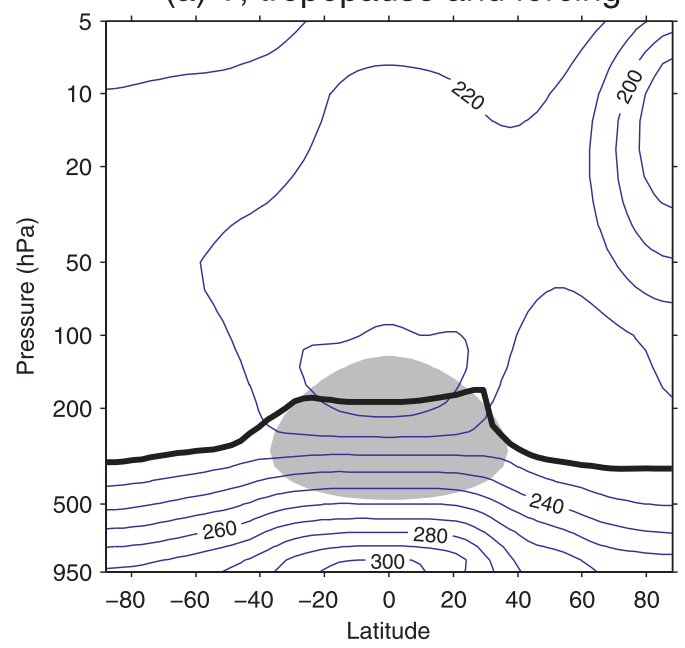

(c) Hadley Cell

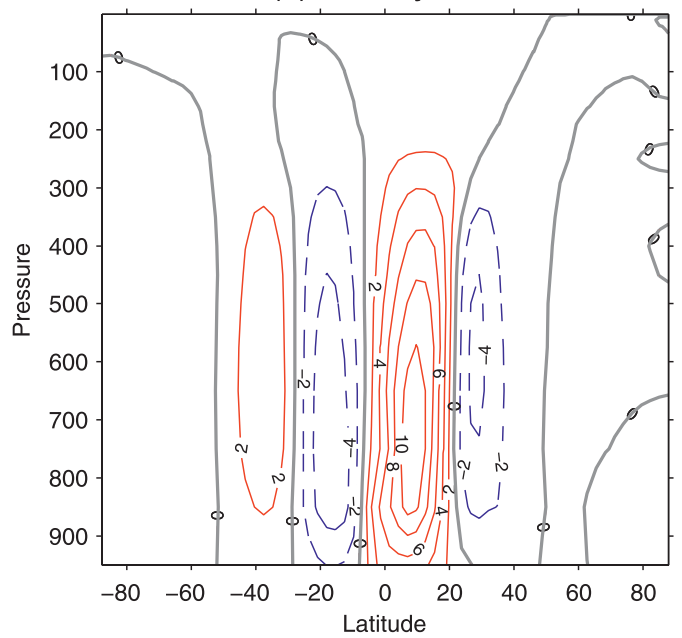

(b) Zonal wind

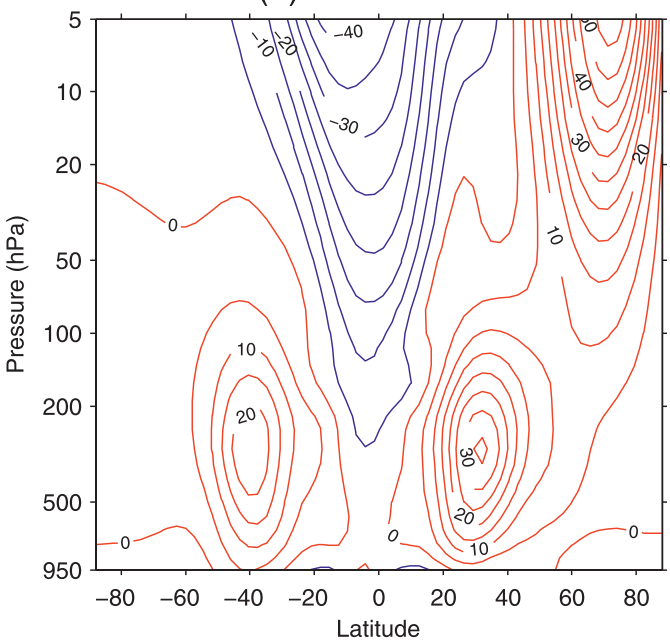

(d) Brewer-Dobson Circulation

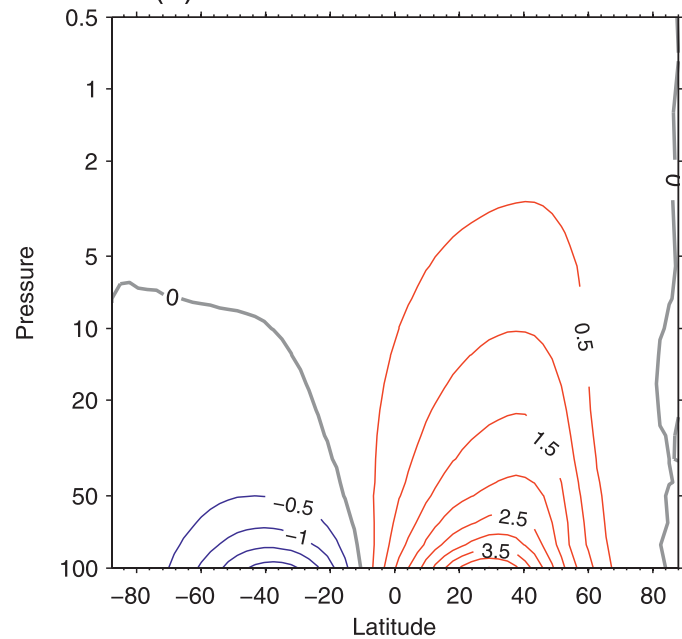

FIG. 1. Climatology of the reference integration (REF). (a) Temperature (contour interval $10 \mathrm{~K}$ ). The shaded region indicates the structure of the imposed low-latitude heating. The tropopause, following the WMO lapse rate definition, is denoted by the thick solid line. (b) Zonal mean zonal wind (contour interval $5 \mathrm{~m} \mathrm{~s}^{-1}$ ). (c) The Eulerianmean meridional circulation, revealing the Hadley and Ferrel cells, quantified by the mass streamfunction (contour interval $2 \times 10^{10} \mathrm{~kg} \mathrm{~s}^{-1}$ ). (d) The Brewer-Dobson circulation, or meridional mass transport through the stratosphere, quantified by the residual mean streamfunction $\Psi^{*}\left(\right.$ contour interval $\left.0.5 \times 10^{9} \mathrm{~kg} \mathrm{~s}^{-1}\right)$.

Figure $1 \mathrm{c}$ illustrates the meridional overturning circulation, with linear pressure scaling to focus on the tropospheric flow. The meridional overturning cells are reasonably represented in REF, despite the model's dry dynamics: the rising branch of the winter Hadley cell is centered near $10^{\circ} \mathrm{S}$, and the stronger, winter hemisphere Ferrel cell spans from $21^{\circ}$ to $51^{\circ} \mathrm{N}$. Its amplitude, about $4 \times 10^{10} \mathrm{~kg} \mathrm{~s}^{-1}$, is comparable to the observed value, but the winter Hadley cell's transport of $11 \times 10^{10} \mathrm{~kg} \mathrm{~s}^{-1}$ is substantially weaker than the $20 \times 10^{10} \mathrm{~kg} \mathrm{~s}^{-1}$ cell in observations (Peixoto and Oort 1992, their Fig. 7.13). The Brewer-Dobson circulation, to be discussed in more detail in section 5 , is shown in Fig. 1d. It is much stronger in the winter hemisphere than in the summer hemisphere, as observed.

TABLE 1. The integrations performed using the Gerber and Polvani model in this study.

\begin{tabular}{ccc}
\hline \hline Name & Resolution & $H_{0}$ values $\left(\mathrm{K} \mathrm{day}^{-1}\right)$ \\
\hline T42 & T42L40 & $-0.1,-0.05,0,0.05,0.1,0.15,0.2$, \\
& & $0.275,0.35,0.425,0.5$ \\
L80 & T42L80 & $0,0.15,0.2,0.275,0.5$ \\
T85 & T85L40 & $0,0.15,0.2,0.275,0.35,0.5$ \\
\hline
\end{tabular}


To this climatology, we now add the tropical heating in Eq. (1), as illustrated by gray shading in Fig. 1a, and first quantify the impact of the heating amplitude $H_{0}$ on the tropical temperature. We define the mean temperature at the tropical tropopause $\overline{T_{p}}$ as the latitudeweighted mean between $25^{\circ} \mathrm{S}$ and $25^{\circ} \mathrm{N}$ at $190 \mathrm{hPa}$ and show its change relative to the REF integration $\Delta \overline{T_{p}}$ in Fig. 2. It varies linearly with the heating amplitude $H_{0}$ in all integrations, irrespective of resolution. This linearity in the tropics is further confirmed by the spatial pattern of the temperature change, shown in Figs. 3a,b. These panels show the latitude-height pattern of the temperature response to the imposed heating in two T42 integrations: one with weak warming of $H_{0}=0.05 \mathrm{~K}$ day $^{-1}$ and one with strong warming of $H_{0}=0.5 \mathrm{~K} \mathrm{day}^{-1}$. These two integrations will be referred to as "WK" and "ST," and are marked by arrows in Fig. 2. Note that the contour intervals between the left and right panels differ by a factor of 10 , corresponding to the ratio of the heating amplitudes $H_{0}=0.05$ and $0.5 \mathrm{~K} \mathrm{day}^{-1}$. The warming is mostly prominent around $200 \mathrm{hPa}$, just above the region of maximum heating, and the temperature response throughout the tropical troposphere is extremely linear with heating amplitude $H_{0}$. In contrast, temperature changes in the stratosphere are of opposite sign, evidence of the regime transition in the extratropical circulation to be explored in the following sections.

To relate our results to comprehensive GCMs, in all subsequent figures, we use the linear relationship between $\Delta \overline{T_{p}}$ and $H_{0}$ to identify all integrations by their tropical temperature response. For example, the weak and strong warming integrations in Fig. 3 correspond to $\Delta \overline{T_{p}}$ warming of 1.4 and $13 \mathrm{~K}$, respectively. Comprehensive GCMs in the Coupled Model Intercomparison Project, phase 3 (CMIP3) scenario integrations indicate that the upper tropical troposphere warms by $\sim 5 \mathrm{~K}$ relative to surface temperature under the $\mathrm{A} 1 \mathrm{~B}$ and $\mathrm{A} 2$ emissions scenarios by the end of the twenty-first century. We explore a range of warming of approximately $15 \mathrm{~K}$, more extreme, but of comparable magnitude to the warming projected under plausible global warming scenarios.

Next we consider the impact of heating on the zonal winds. Figures $3 \mathrm{c}$, d show that the zonal wind response to tropical warming has a distinct dipolar pattern in the troposphere in both integrations. The pattern, to first order, characterizes a poleward shift of the tropospheric jet streams. The dipolar structure of the response fades away in the upper-troposphere/lower-stratosphere region near $200 \mathrm{hPa}$ where a simple acceleration of the tropospheric jet on its poleward flank is found. This net acceleration is associated with a temperature decrease in the high latitudes just above the tropopause, observed in

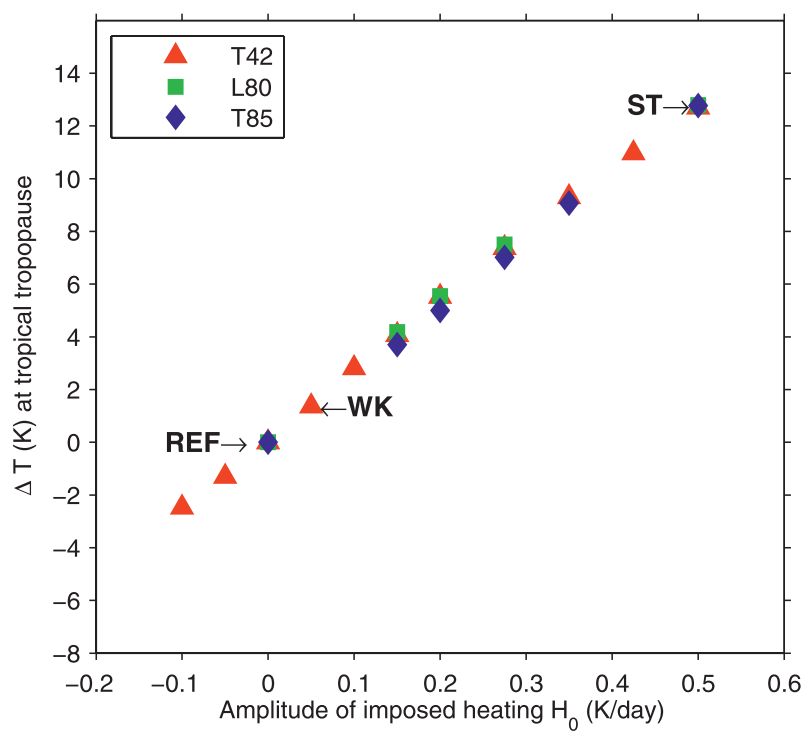

FIG. 2. The direct temperature response to heating in the upper tropical troposphere as quantified by the change in the zonal mean tropical tropopause temperature $\Delta \overline{T_{p}}$, averaged between $25^{\circ} \mathrm{N}$ and $25^{\circ} \mathrm{S}$ at $190 \mathrm{hPa}$, relative to the reference integration (REF). The horizontal axis indicates the thermal forcing amplitude $H_{0}$. Here WK and ST denote two T42 integrations with $H_{0}=0.05$ and $0.5 \mathrm{~K} \mathrm{day}^{-1}$, respectively, shown in further detail in Fig. 3.

both the weak and strong warming integrations in Figs. 3a,b. A similar temperature feature was noted by Butler et al. (2010), and we suspect that it is the thermal signature associated with the jet shift.

In the stratosphere the dipolar structure of the wind response reappears, suggesting an acceleration and expansion of the stratospheric polar vortex. The response is highly nonlinear, however, as already noted in the temperature fields above. Significant nonlinearity also exists in the response of the near-surface winds, as suggested by the shift in the zero contour, but is not readily visible in this figure, as the contour interval was chosen to illustrate the upper tropospheric and stratospheric response.

The nonlinear response of the surface winds and stratospheric circulation suggests a change in the $e d d y$ driven circulation. To emphasize that the mechanically driven circulation can respond very nonlinearly to an otherwise smooth increase in thermal forcing, we first establish the gradual response of the tropical, thermally driven circulation. As found by Butler et al. (2010), the Hadley cell of the idealized GCM expands and weakens in response to the imposed heating. Here we extend their results and show that the amplitude of the response is linearly related with the heating. We quantify the change of the Hadley cell strength by plotting the difference in the total mass transport by the winter cell, as compared to the REF integration, in Fig. 4a. The 
(a) $\Delta \mathrm{T}$ for weak warming

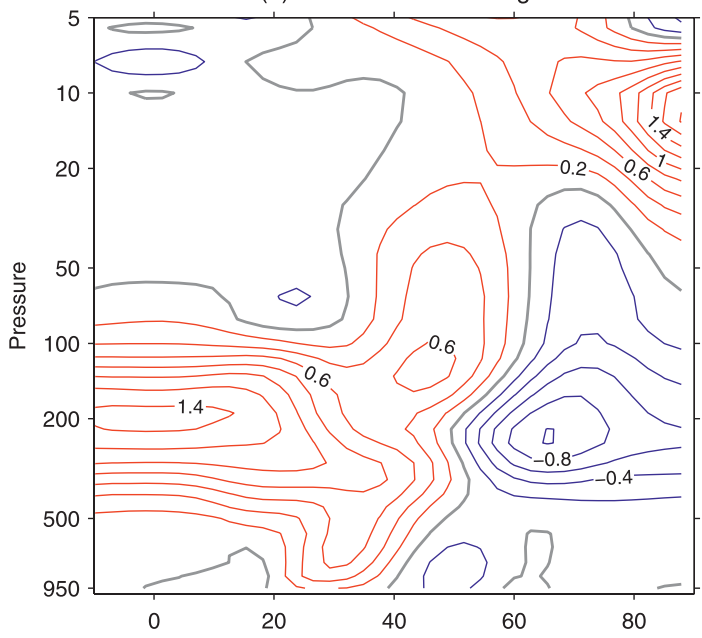

(c) $\Delta \mathrm{U}$ for weak warming

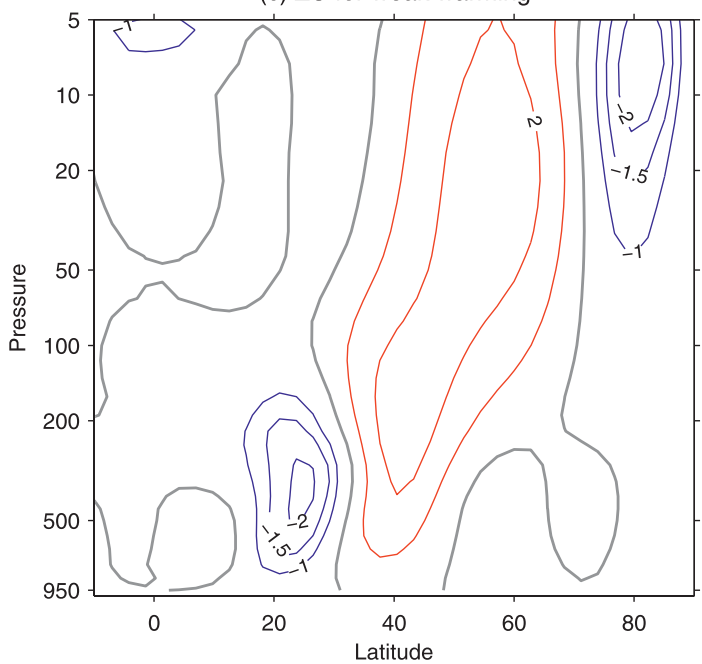

(b) $\Delta \mathrm{T}$ for strong warming

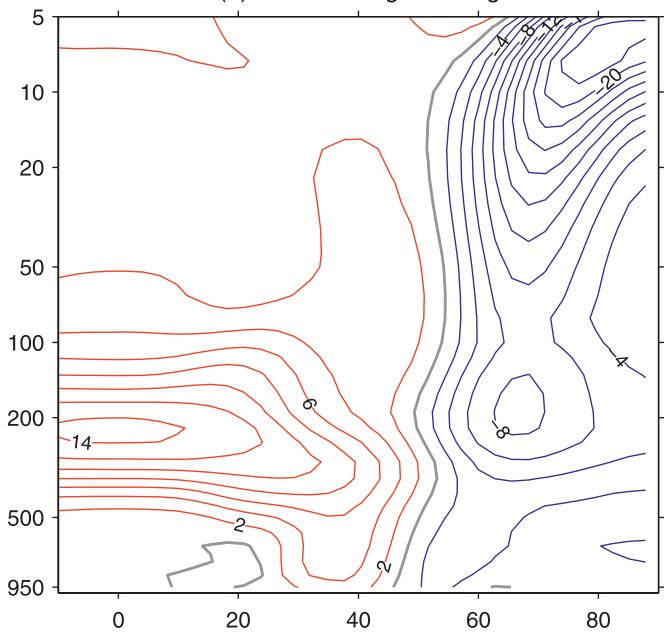

(d) $\Delta \mathrm{U}$ for strong warming

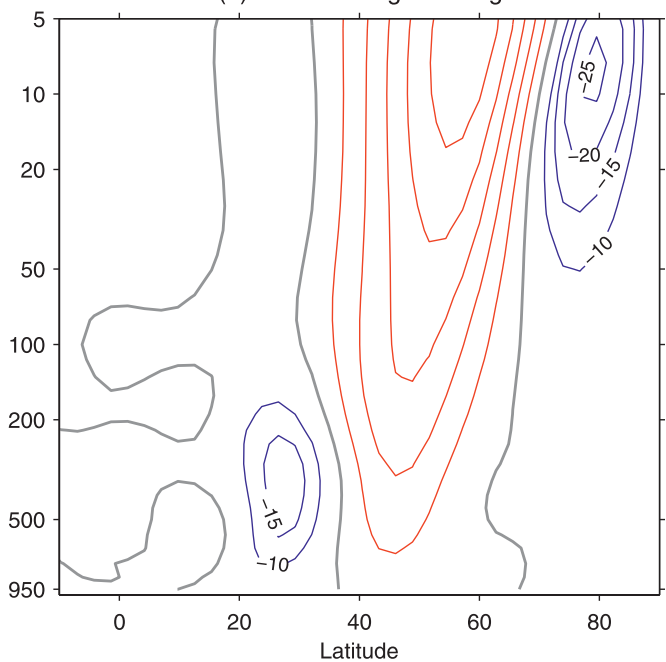

FIG. 3. The zonal mean response to tropical warming. The change from the reference integration REF (a),(c) in a weak warming integration $\left(H_{0}=0.05 \mathrm{~K} \mathrm{day}^{-1}\right.$, marked as WK in Fig. 2), and (b),(d) in a strong warming integration (with $H_{0}=0.5 \mathrm{~K} \mathrm{day}^{-1}$, marked as ST in Fig. 2). The difference in (top) zonal mean temperature (contour interval $0.2 \mathrm{~K}$ for WK and $2 \mathrm{~K}$ for ST) and (bottom) zonal mean zonal wind are contoured. Contours of the zonal wind are $\ldots,-2,-1.5,-1,0,1,2,3 \ldots \mathrm{m} \mathrm{s}^{-1}$ for WK and $\ldots,-20,-15,-10,0,10,20,30,40,50 \ldots \mathrm{m} \mathrm{s}^{-1}$ for ST; contour intervals in ST-REF are 10 times of that in WK-REF so that the figures would be identical if the response were purely linear. The gray lines denote zero values.

change in its width is quantified in Fig. $4 \mathrm{~b}$ by the shift of the zero value of the 500-hPa streamfunction. A linear fit indicates a $0.6^{\circ}-0.7^{\circ}$ latitude shift per kelvin of uppertroposphere warming. The expansion rate is not entirely linear with temperature, particularly for the "global cooling" experiments and the extreme warming cases $\left(\Delta \overline{T_{p}}>10 \mathrm{~K}\right)$. The weakening of the Hadley cell also exhibits some weakly nonlinear behavior. Doubling the horizontal or vertical resolution has a small effect on the response, but the overall structure is robust.

We compare the expansion of the Hadley cell in our model with two theoretical scaling laws. The first is the scaling argument based on the angular momentum conservation by Held and Hou (1980). They proposed that the extent of the Hadley cell for a nearly inviscid axisymmetric circulation should scale as

$$
\Phi_{H}=\left(\frac{5 g H_{t}}{3 \Omega^{2} a^{2}} \frac{\Delta_{h}}{\theta_{0}}\right)^{1 / 2}
$$

where $g=9.8 \mathrm{~m} \mathrm{~s}^{-2}, a$ is the radius of the earth, $\Omega$ is the angular speed of the rotation of the earth, $\Delta_{h}(\sim 70 \mathrm{~K}$ in the REF integration) is the equator-to-pole temperature difference, $\theta_{0}(300 \mathrm{~K}$ in $\mathrm{REF})$ is the global mean 
(a) Change of $\mathrm{HC}$ strength

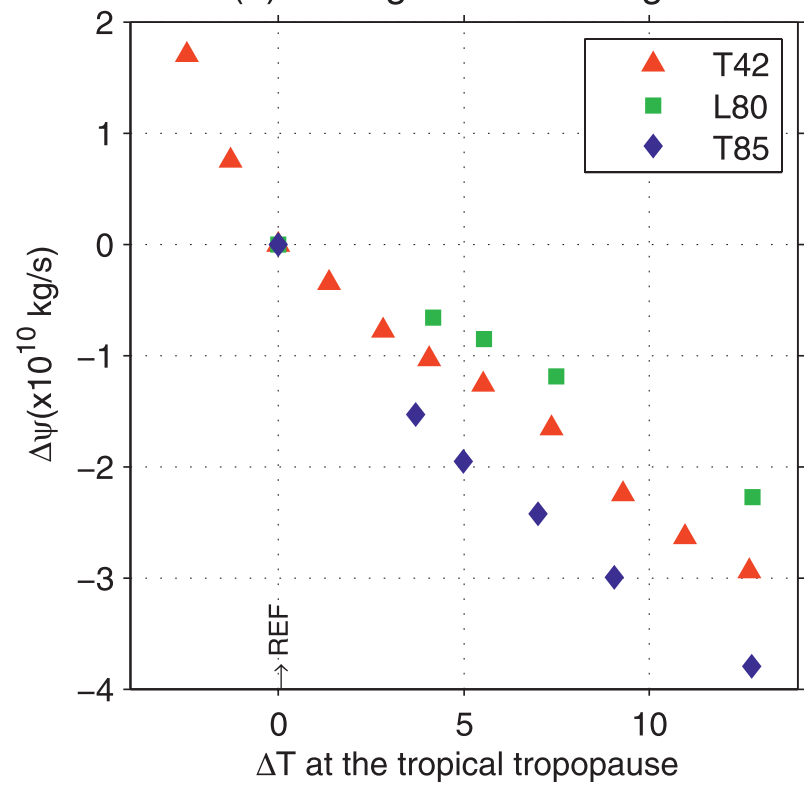

(b) Change of $\mathrm{HC}$ edge

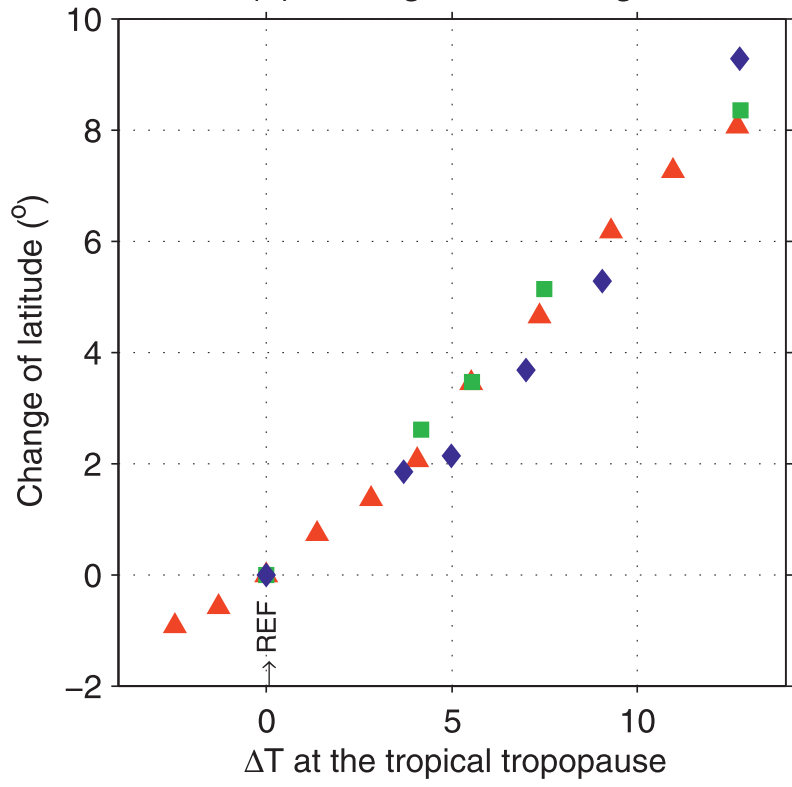

FIG. 4. The change in the (a) total mass transport and (b) latitudinal extent of the Hadley cell ( $\Psi=0$ at $500 \mathrm{hPa}$ in the Northern Hemisphere) as a function of warming of the tropical tropopause.

temperature, and $H_{t}$ is the height of the tropical tropopause estimated as $H_{t}=-7500 \times \ln \left(P_{T} / P_{0}\right)\left(P_{T}\right.$ is the pressure at the tropopause, and $P_{0}=1000 \mathrm{hPa}$ the surface pressure). The second scaling, proposed by Held (2000), argues that the width is set by the latitude at which the mean vertical shear makes the flow baroclinically unstable. Here the Hadley cell width is largely determined by the midlatitude eddies and scales as

$$
\Phi_{c} \sim\left(\frac{g H_{e t}}{\Omega^{2} a^{2}} \frac{\Delta_{v}}{\theta_{0}}\right)^{1 / 4}
$$

where $H_{e t}$ is the latitude-weighted tropopause height between $20^{\circ}$ and $40^{\circ}$ and $\Delta_{v}$ is the gross dry stability estimated as the difference in $\theta$ between the surface and tropopause in the subtropics $\left(20^{\circ}-40^{\circ} \mathrm{N}\right)$.

Idealized modeling studies (e.g., Schneider 2004; Schneider and Walker 2006; Frierson et al. 2007) and a study based on IPCC AR4 models ( $\mathrm{Lu}$ et al. 2008) suggest that the latter scaling, based on midlatitude eddy influence, better captures the expansion of the Hadley cell. This is confirmed in Fig. 5, which compares the estimated Hadley cell width based on the two theoretical arguments with values diagnosed from the integrations. The latitude of the poleward edge of the Hadley cell varies from $20^{\circ}$ to $40^{\circ} \mathrm{N}$ over the range considered. The scaling based on the angular momentum conservation and energy closure is relatively insensitive to the lowlatitude warming, while the scaling based on the midlatitude eddies seems to be more qualitatively, if not entirely quantitatively, in line with the computed Hadley expansion. This confirms that momentum divergence associated with midlatitude eddies exerts some control on the tropical Hadley circulation in our model.

In summary then, the tropical response of our GCM to global warming-like heating is very similar to established predictions of climate change. This confirms the findings of Butler et al. (2010), who showed that the circulation response of idealized models to simple warming of the tropical upper troposphere well approximates the response seen in comprehensive models. With this in hand, we now turn to the more surprising circulation changes in our integrations.

\section{Abrupt climate change}

The nonlinear response of the stratospheric temperature and zonal winds, seen in Fig. 2, reflects the more complex behavior of the extratropical, eddy-driven circulation. To explore this nonlinearity we show how the amplitude and structure of the high-latitude circulation change as a function of the tropical warming $\Delta \overline{T_{p}}$. The dipolar pattern in the tropospheric wind response in Figs. $3 \mathrm{c}, \mathrm{d}$ is associated with both a poleward shift and strengthening of the tropospheric jet. To differentiate these two effects, in Fig. 6 we plot the latitude and strength of the jet maxima at three levels to characterize the response of the near-surface, upper-troposphere, and stratospheric jets. The upper- and lower-tropospheric westerlies shift poleward with increased warming, while 


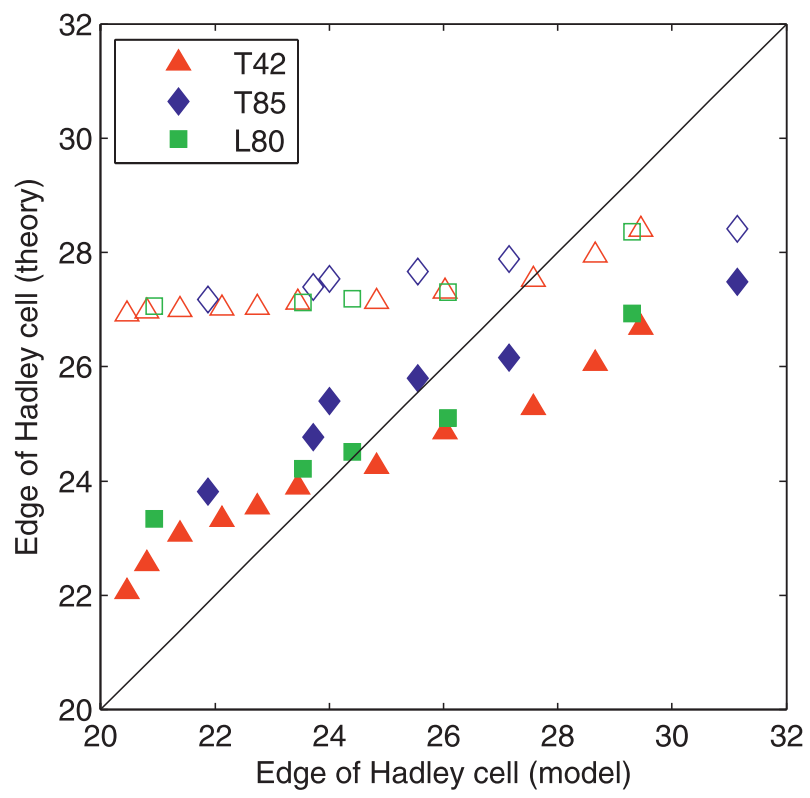

FIG. 5. The Held-Hou (1980, open symbols) and Held (2000, closed symbols) scaling for the Hadley cell width (vertical axis) vs the actual values for all integrations (horizontal axis). If the theory were perfect, the data should exhibit a slope of 1 ; both theories underestimate the sensitivity of the Hadley cell, but Held (2000) is more accurate.

the stratospheric polar jet broadens, forcing the maximum winds equatorward.

A key result of this study is that the zonal mean zonal winds at $850 \mathrm{hPa}$ reveal a regime transition in the barotropic, eddy-driven circulation when the tropical warming exceeds approximately $5 \mathrm{~K}$ (Fig. 6a). The nearsurface wind maximum jumps poleward, and the trend in its amplitude suddenly reverses sign (Fig. 6b). The nearsurface jet maximum is located near $30^{\circ} \mathrm{N}$ in the REF integration, slowly shifts poleward with increased warming until a dramatic $10^{\circ}$ shift to $40^{\circ} \mathrm{N}$, and then resumes its poleward march with increased warming. Before the transition the wind maximum weakens slowly with increased warming; afterward, it increases rapidly with further warming. The exact transition point is somewhat sensitive to resolution, occurring slightly later in the T85 integrations, but the regime change itself is robust.

While the low-level winds are important for coupling to the ocean and surface weather patterns, the $10^{\circ}$ jump of the near-surface wind maximum may overstate the circulation change. The weak curvature of the surface winds makes this metric quite sensitive to external perturbation (Baldwin 2003). It is thus important to consider the whole circulation. The shift of the westerly jet in the upper troposphere, shown in Fig. 6c, is by comparison fairly smooth. The latitude of the upper-tropospheric jet depends primarily on temperature constraints associated with thermal wind balance. Thus, the rapid movement of the surface winds associated with a shift in the eddy momentum convergence does not cause an abrupt shift in the upper-level winds. The amplitude of the upper-level jet, however, reflects the regime change in the eddydriven circulation; as with the $850-\mathrm{hPa}$ winds, the jet weakens slightly with increased warming until the $5-\mathrm{K}$ threshold, after which point the winds begin to increase with additional warming. The trends of $U_{\max }$ at $300 \mathrm{hPa}$ are consistent among different resolutions, although the absolute value of the T85 winds at this level are $\sim 2 \mathrm{~m} \mathrm{~s}^{-1}$ less than at $\mathrm{T} 42$.

The regime transition is also readily apparent in the stratospheric winds, as shown in Figs. 6e,f. Initially the latitude of $U_{\max }$ at $10 \mathrm{hPa}$ drifts very weakly, accompanied by little (if any) acceleration of the wind strength. Beyond the point of abrupt change, however, the latitude of $U_{\max }$ shifts from $70^{\circ}$ to $60^{\circ} \mathrm{N}$, and the amplitude of the winds increases rapidly from $50-60 \mathrm{~m} \mathrm{~s}^{-1}$ in the reference integration to $\sim 80 \mathrm{~m} \mathrm{~s}^{-1}$ in the integration with $\Delta \overline{T_{p}} \cong 13 \mathrm{~K}$. As in earlier plots, the transition is delayed to warmer forcing levels in the T85 integrations, but the regime transition itself is robust.

The stratospheric winds at $10 \mathrm{hPa}$ are closely related to the temperature of the polar vortex in the lower stratosphere by thermal wind balance, a stronger vortex corresponding to colder temperatures. This is confirmed by plotting the area-weighted polar cap temperature $T_{\text {cap }}$ averaged from $60^{\circ}$ to $90^{\circ} \mathrm{N}$ at $50 \mathrm{hPa}$ in Fig. 7 . We see a similar (albeit of opposite sign) trend structure to the $10-\mathrm{hPa}$ vortex wind plots in Figs. 6e,f. There is very little change in the polar cap temperature at $50 \mathrm{hPa}$ until the regime transition, after which point the temperature drops markedly with increased tropical warming. In the extreme warming cases, the temperature bottoms out near $205 \mathrm{~K}$. This is the same temperature found at this pressure level in the original Polvani and Kushner (2002) model with no topography. Hence, the stratospheric polar vortex has become more like that of the Southern Hemisphere: the tropical warming has completely undone the influence of the surface topography.

It is important to stress that the stratospheric cooling is here completely driven by the dynamical response of the stratospheric circulation to upper-tropospheric warming in the tropics. If coupled to stratospheric chemistry, it is possible that the change would be intensified. Cooling increases the formation of polar stratospheric clouds, permitting heterogenous chemistry and rapid ozone loss. Indeed, record low ozone levels were observed over the Northern Hemisphere in the 2010/11 winter because the polar vortex was relatively undisturbed, leading to colder than average temperatures (Hurwitz et al. 2011). 
(a) Latitude of $U_{\max }$ at $850 \mathrm{hPa}$

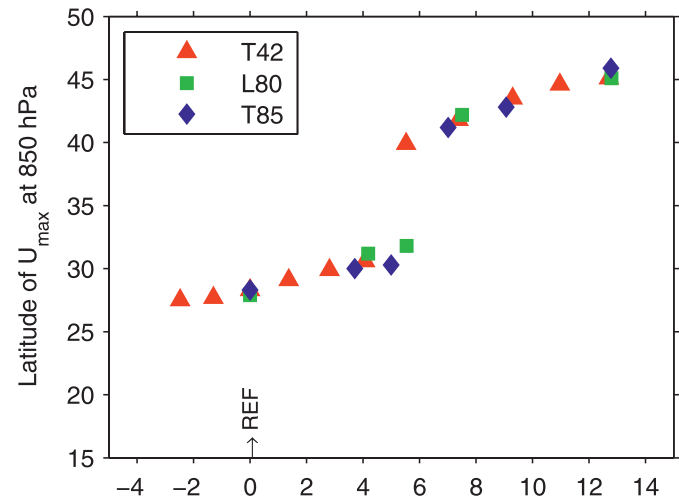

(c) Latitude of $U_{\max }$ at $300 \mathrm{hPa}$

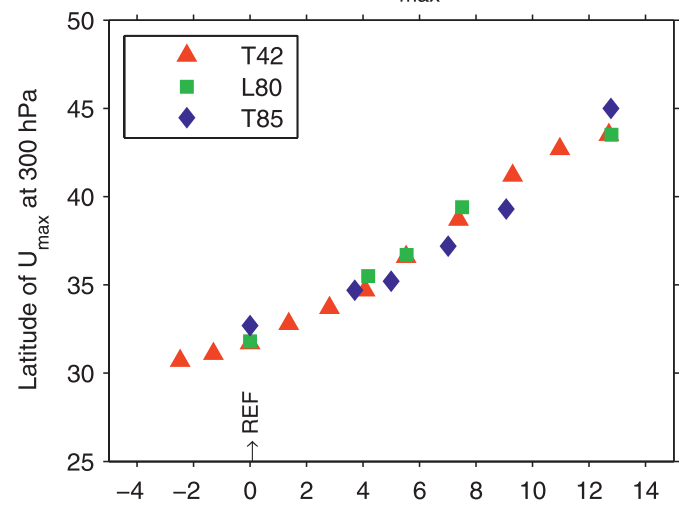

(e) Latitude of $U_{\text {max }}$ at $10 \mathrm{hPa}$

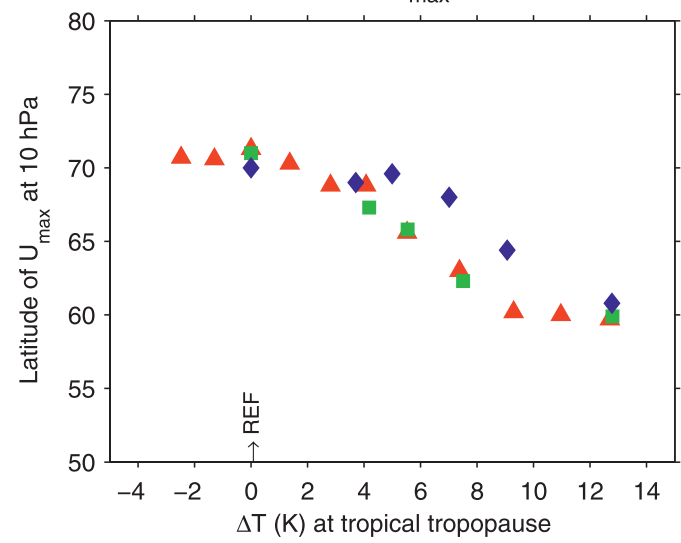

(b) $U_{\max }$ at $850 \mathrm{hPa}$

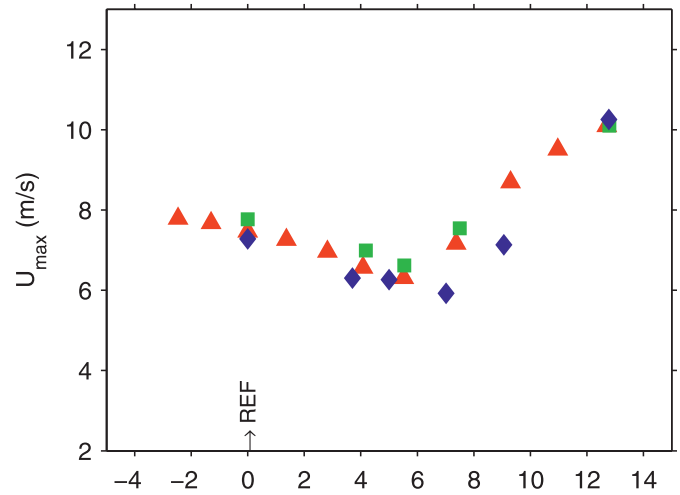

(d) $U_{\max }$ at $300 \mathrm{hPa}$

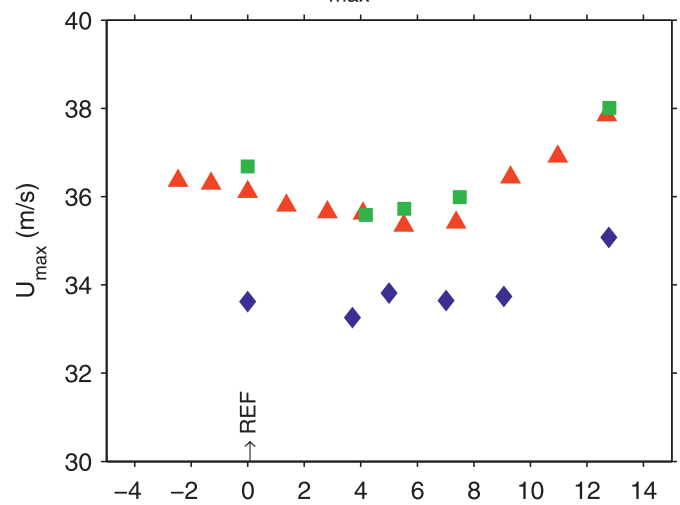

(f) $U_{\max }$ at $10 \mathrm{hPa}$

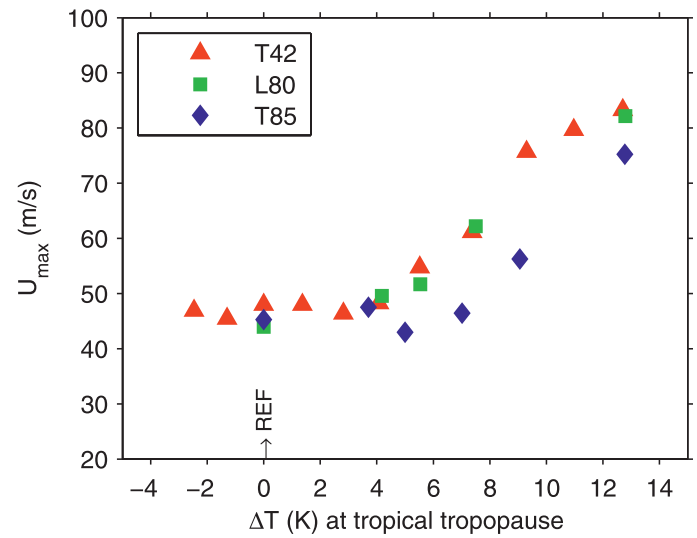

FIG. 6. Evidence of abrupt change in the eddy-driven circulation in the near-surface, upper-tropospheric, and stratospheric jets: (a),(c),(e) latitude of the maximum zonal mean zonal winds $U_{\max }$ and (b),(d),(f) amplitude of $U_{\max }$, as a function the tropical warming, based (top) at $850 \mathrm{hPa}$, (middle) at $300 \mathrm{hPa}$, and (bottom) at $10 \mathrm{hPa}$.

\section{Changes in stratosphere-troposphere coupling}

The cooling of the stratosphere suggests a substantial change in the coupling between the stratosphere and troposphere in our model. The stratospheric circulation is tightly coupled to the tropospheric circulation on intraseasonal time scales in our reference integration, as specifically constructed by Gerber and Polvani (2009). Planetary waves induced by the surface topography propagate into the stratosphere intermittently, initiating stratospheric sudden warmings (SSWs). The breakdown of the polar vortex in turn influences the tropospheric 


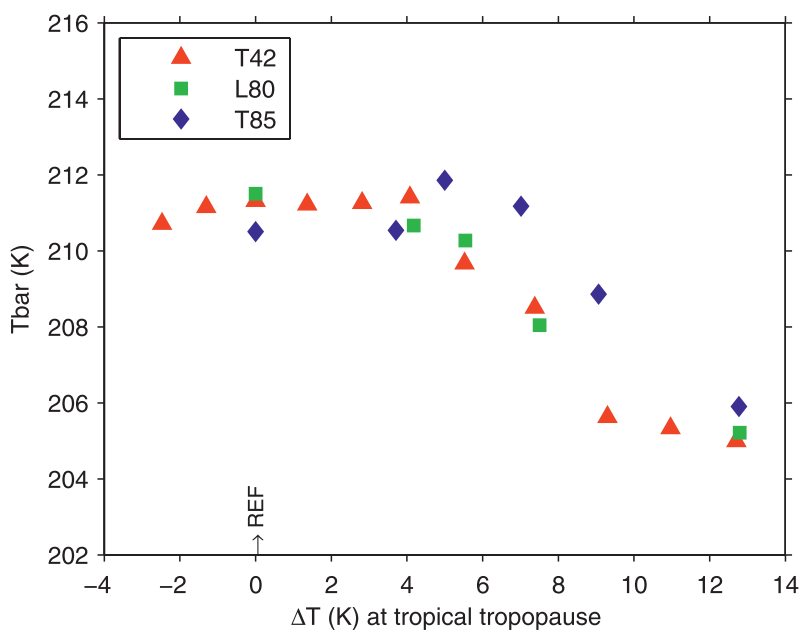

FIG. 7. The polar cap temperature (K) defined as the latitudeweighted mean temperature between $60^{\circ}$ and $90^{\circ} \mathrm{N}$ at $50 \mathrm{hPa}$.

jet, shifting the tropospheric jets poleward and increasing the time scales of the tropospheric annular mode (Gerber et al. 2009).

The Brewer-Dobson circulation of the reference integration was shown in Fig. 1d. The residual mean streamfunction $\Psi^{*}$ is derived from the residual circulations $\left([v]^{*},[\omega]^{*}\right)$, defined by

$$
[v]^{*}=[v]-\frac{\partial\left(\left[v^{\prime} \theta^{\prime}\right] /[\theta]_{p}\right)}{\partial p}=\frac{\partial \Psi^{*}}{\partial p}
$$

and

$$
\begin{aligned}
{[\omega]^{*} } & =[\omega]+\frac{1}{a \cos \phi} \frac{\partial\left(\left[v^{\prime} \theta^{\prime}\right] \cos \phi /[\theta]_{p}\right)}{\partial \phi} \\
& =-\frac{1}{a \cos \phi} \frac{\partial\left(\Psi^{*} \cos \phi\right)}{\partial \phi},
\end{aligned}
$$

where the brackets denote the zonal mean, $v^{\prime}$ and $\theta^{\prime}$ are deviations from the zonal mean meridional wind and potential temperature, and $\Psi^{*}$ approximates the Lagrangian transport of mass through the stratosphere (e.g., Andrews et al. 1987). At equilibrium the extratropical residual meridional velocity results from a balance between the wave drag and the Coriolis force, as described in downward control theory (Haynes et al. 1991). The wave drag is significantly enhanced by upward propagating planetary stationary waves forced by the surface topography; in an integration with identical setting except for a flat lower boundary, the winter branch is only slightly stronger than the summer branch, as expected.

Figures $8 \mathrm{a}, \mathrm{b}$ show the difference of the residual mean streamfunction $\Psi^{*}$ between the reference and the WK and ST integrations, respectively. In the weak warming case WK, $\Psi^{*}$ increases in the Northern Hemisphere and decreases in the Southern Hemisphere, yielding an overall acceleration of BDC. In the strong warming case ST, $\Psi^{*}$ decreases significantly over the whole stratosphere with a maximum decrease between $40^{\circ}$ and $60^{\circ} \mathrm{N}$, suggesting a dramatic deceleration of the circulation. The reversal in the circulation trend explains the opposite sign of the temperature responses in the stratosphere seen in Figs. 3a,b. Under moderate warming, increased upwelling drives adiabatic expansion and cooling in the tropical stratosphere, while increased downwelling drives compression and warming in the extratropical stratosphere. Under strong warming, the weakening of the circulation warms the tropics and cools the extratropics.

Following Butchart et al. (2006) and Li et al. (2008), we quantify the BDC strength in all integrations by computing the net upward mass flux in the tropics:

$$
\left\langle M^{*}\right\rangle=\frac{1}{g} \int_{\phi_{s}}^{\phi_{n}} 2 \pi r_{0}^{2} \cos \phi[\omega]^{*} d \phi,
$$

where $r_{0}$ is the earth's radius and $\phi_{s}$ and $\phi_{n}$ are the turning latitudes where the residual mean vertical velocity $[\omega]^{*}$ changes sign. Figure 9 shows $\left\langle M^{*}\right\rangle$ at $100 \mathrm{hPa}$; similar plots are found at other levels in the lower stratosphere. In the T42 and L80 integrations, the tropical upwelling increases by up to $10 \%$, reaching a maximum when the tropical warming $\Delta \overline{T_{p}}$ nears $4 \mathrm{~K}$. Beyond this level of warming, however, further increase in $\Delta \overline{T_{p}}$ leads to an abrupt reduction of the tropical upwelling. Once $\Delta \overline{T_{p}}$ exceeds $9 \mathrm{~K},\left\langle M^{*}\right\rangle$ is $10 \%$ weaker than in the reference integration. The T85 integrations indicate the same nonlinearity of the BDC, but the transition is delayed. It is noteworthy that the stratospheric response appears more sensitive to horizontal than vertical resolution.

An abrupt transition of the BDC trend has not been reported in other GCMs, but there is possible evidence for it in previous studies with idealized models. Eichelberger and Hartmann (2005) observed an acceleration of the BDC due to warming in the tropics, while Butler et al. (2010) found a deceleration. The amplitude of the warming at the tropics, however, was quite different in the two studies, around $5 \mathrm{~K}$ in Eichelberger and Hartmann (2005, see their Fig. 2), and $10 \mathrm{~K}$ in Butler et al. (2010, see their Fig. 2). These amplitudes are near the extremes of the two regimes identified in our model. Hence, our integrations may reconcile these two idealized AGCM results. This highlights the importance of exploring the entire parameter space. The acceleration of BDC for weak-tomoderate warming is in agreement with projections by 
(a) $\Delta \Psi^{*}$ for weak warming

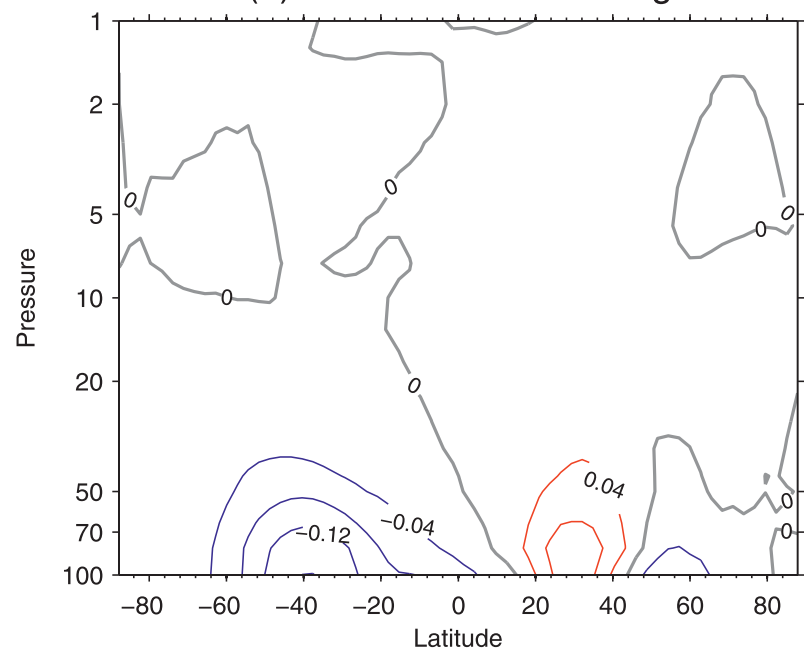

(b) $\Delta \Psi^{*}$ for strong warming

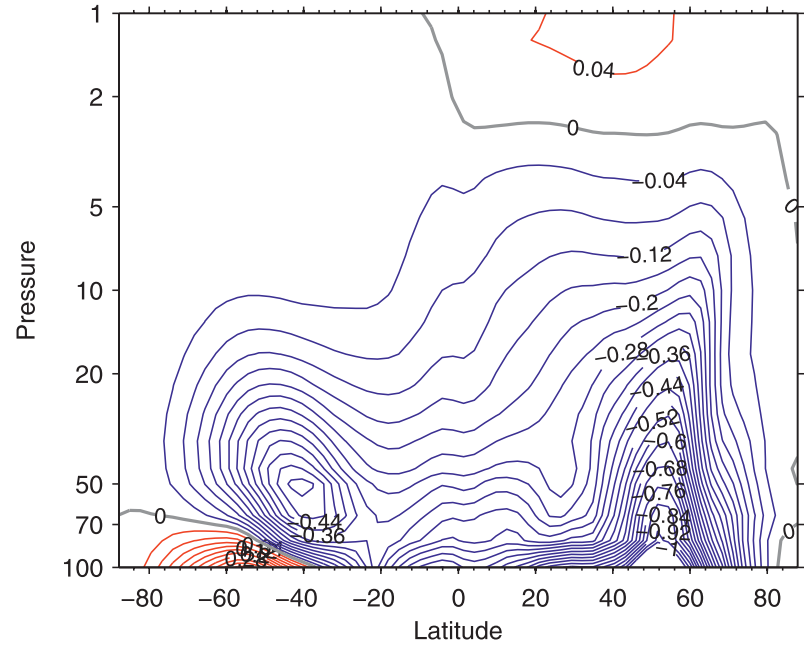

FIG. 8. (a) The difference of the residual streamfunction $\Delta \Psi^{*}$ between the weak warming integration WK and REF (contour interval $0.04 \times 10^{9} \mathrm{~kg} \mathrm{~s}^{-1}$ ). (b) As in (a), but for the difference between the strong warming integration ST and REF. Gray lines denote the zero contour.

nearly all of the models participating Chemistry Climate Model Validation Activity (Butchart et al. 2006, 2010). Observations by Engel et al. (2009) suggest that the observed BDC may be weakening, but the large uncertainty in measurements does not permit one to rule out the trend suggested by models (e.g., Garcia et al. 2011).

The reversal of the mean overturning circulation trend is also related to significant changes in the intraseasonal variability of the stratosphere. SSW events represent the bulk of intraseasonal variability in the polar winter stratosphere of the Northern Hemisphere. Following the World Meteorological Organization convention,

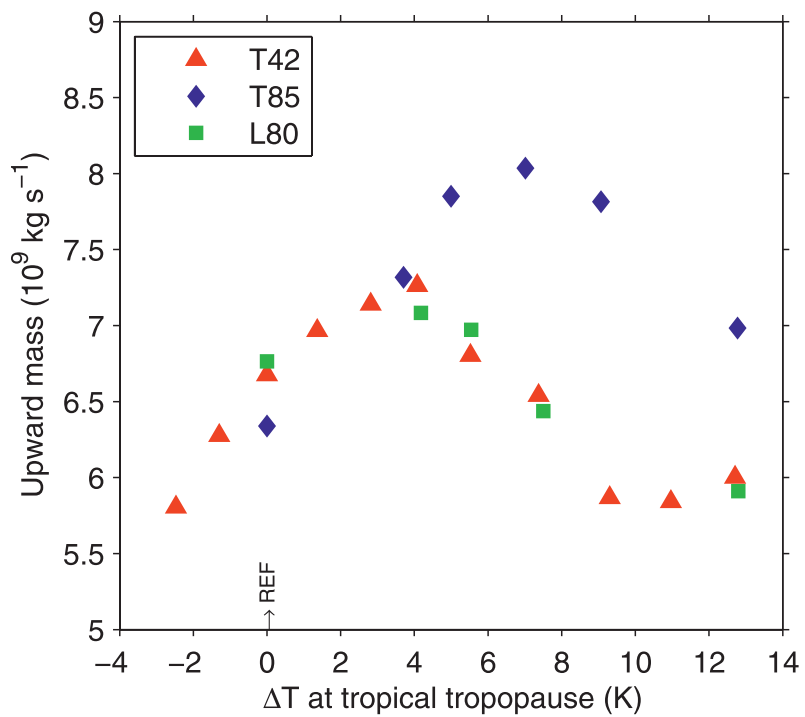

FIG. 9. The strength of the Brewer-Dobson circulation as a function of tropical warming, quantified by the total upward mass flux at $100 \mathrm{hPa}$ in the tropics.

we identify SSWs as instances when the zonal mean zonal wind at $10 \mathrm{hPa}$ and $60^{\circ} \mathrm{N}$ becomes easterly, and an event is counted only if no prior SSW had been recorded in the preceding 40 days. Figure 10 shows the number of SSWs per decade as a function of tropical warming. For weak to moderate tropical warming, $\Delta \overline{T_{p}}<5 \mathrm{~K}$, the frequency of SSWs does not appear to change appreciably. When the warming passes the 5-K threshold, however, the frequency of SSWs decreases rapidly, all but disappearing in the extremely warm integrations. With the shutdown of SSWs, the model's Northern Hemisphere becomes more like the Southern Hemisphere, where SSWs occur very infrequently.

One pathological T85 integration $\left(\Delta \overline{T_{p}}=5.5 \mathrm{~K}\right)$ around the regime transition exhibits an exceedingly high frequency of SSWs, almost 13 decade $^{-1}$. Closer inspection of the stratospheric variability in this integration (not shown) suggests that the high number of warmings is not caused by a radical change in stratospheric variability, but rather a subtle change in the 10-hPa climatology and the threshold definition of SSWs, as discussed by McLandress and Shepherd (2009a). To confirm this hypothesis, we consider an alternative measure of stratospheric vortex variability that does not depend on a threshold. Figure 10b shows the standard deviation $\sigma$ of the daily zonal mean zonal wind at $60^{\circ} \mathrm{N}, 10 \mathrm{hPa}$. The overall variability of the vortex increases near the regime transition at all resolutions and then drops down again afterward. This is typical of a regime transition for dynamical systems (Scheffer et al. 2009). 
(a) Frequency of SSWs

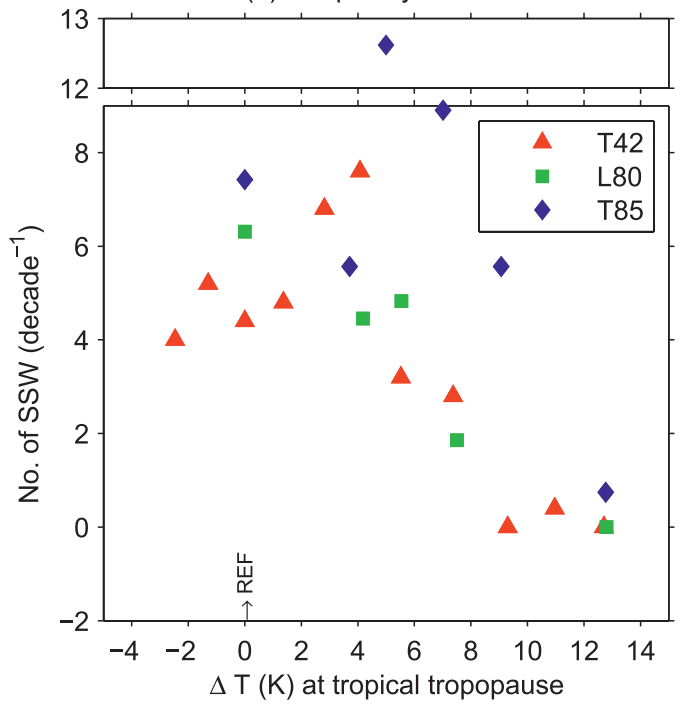

(b) $\sigma$ of $U(10 \mathrm{hPa}, 60 \mathrm{~N})$

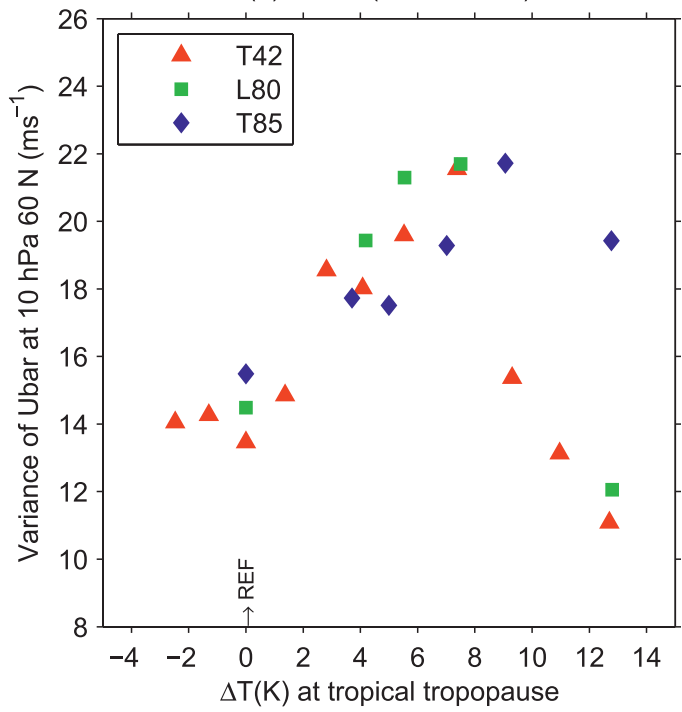

FIG. 10. The variability of polar vortex as a function of tropical warming: (a) frequency of stratospheric sudden warming events and (b) standard deviation of the zonal mean wind at $10 \mathrm{hPa}, 60^{\circ} \mathrm{N}$. A different scale is used for one T85 integration with dramatically more frequent SSWs.

Previous studies have examined SSW trends in comprehensive climate models. Charlton-Perez et al. (2008) found a small positive trend in the frequency of SSWs over the course of the twenty-first century, consistent with our model under weak to moderate warming. McLandress and Shepherd (2009a) found that the frequency of SSWs, as defined by the WMO criteria, increased by $60 \%$ by the end of the twenty-first century in the Canadian Middle Atmosphere Model, but the trend was largely a consequence of a weakening climatological mean winds at $60^{\circ} \mathrm{N}, 10 \mathrm{hPa}$ and not a fundamental change in the variability. Neither study observed a sudden drop off in stratosphere-troposphere coupling, but both were based on moderate scenario forcings, not the more extreme warming of over $10 \mathrm{~K}$ considered here.

Our analysis suggests that a stark transition in the vertical coupling of the atmosphere may be possible: in the reference climate, the stratosphere and troposphere are tightly coupled on intraseasonal time scales, as in the observed Northern Hemisphere. In an extreme warm climate the stratosphere and troposphere are more decoupled at intraseasonal time scale, as observed in the Southern Hemisphere. Figure 11 diagnoses the dynamics behind the changes, showing the Eliassen-Palm (E-P) fluxes in the REF and ST integrations. As discussed by Edmon et al. (1980), the E-P flux vectors characterize the propagation of wave activity in the atmosphere and allow one to diagnose the eddy forcing of the zonal mean wind. The climate transition is characterized by a deflection of wave activity away from the stratosphere toward the subtropical troposphere.

The downward-pointing vectors from the stratosphere to the troposphere in the difference plot reflect a reduction of the upward wave activity flux, not a new source of waves in the stratosphere. Reduced wave driving goes hand in hand with fewer SSW events and a weakening of the Brewer-Dobson circulation, which owes its existence to the mechanical forcing by waves breaking in the stratosphere. The weakening of the meridional circulation in turn reduces adiabatic warming in the extratropical stratosphere, cooling and strengthening the vortex. Wave activity that used to propagate upward into the stratosphere instead propagates equatorward in the upper troposphere. The eddy-driven jet and surface westerlies are maintained by the net export of wave activity from the extratropical baroclinic region to the subtropics. The increased equatorward wave flux reflects the poleward shift of the jet.

\section{Regime behavior}

The abrupt change in the eddy, or wave-driven circulation highlighted by the shift in the barotropic jet and the weakening of the mechanically driven circulation in the stratosphere suggests the presence of two distinct atmospheric regimes in our model: a "present day" state and a "warm world" state. In the former wave activity intermittently propagates into the stratosphere, coupling the upper atmosphere to the lower atmosphere on 
(a) EP flux for REF T42

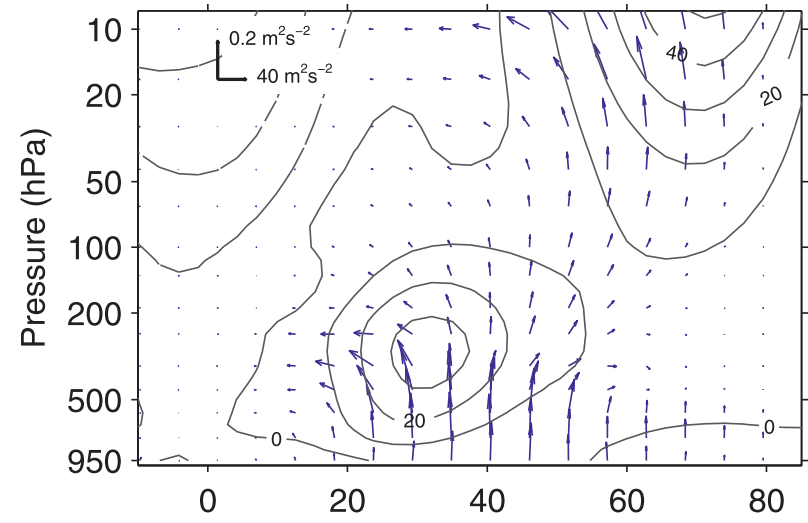

(b) EP flux for ST T42

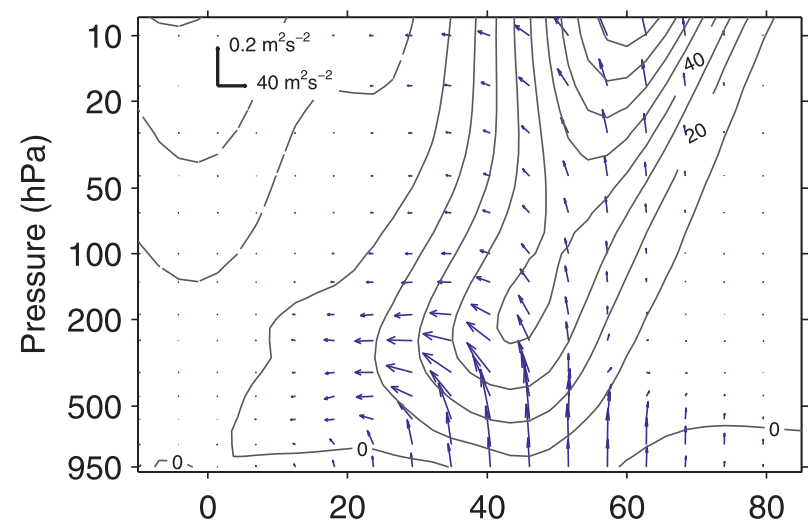

(c) Diff

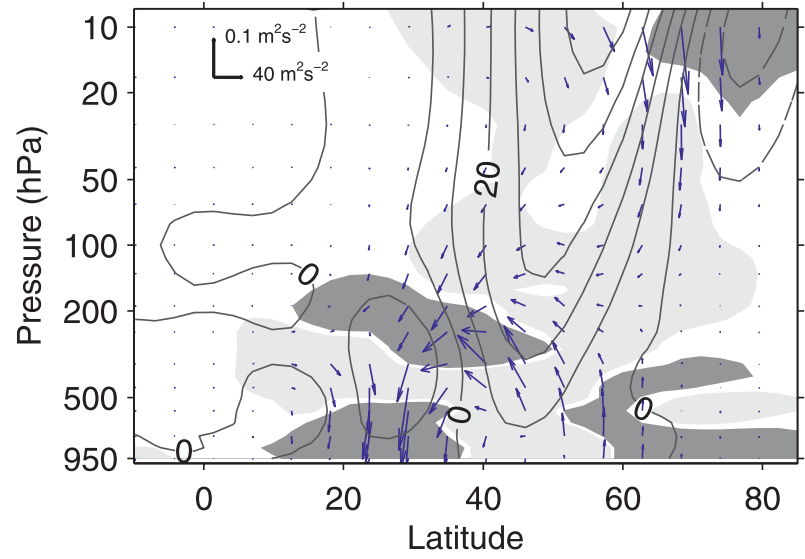

FIG. 11. Changes in wave driving in response to tropical warming, as characterized by the Eliassen-Palm flux: (a) E-P flux vectors $\left(\mathrm{m}^{2} \mathrm{~s}^{-2}\right)$ and zonal mean zonal wind (every $10 \mathrm{~m} \mathrm{~s}^{-1}$ ) for the reference case with T42 resolution; (b) as in (a), but for the strong warming integration; and (c) difference in zonal mean zonal wind and E-P flux vectors. Changes in the E-P divergence are shaded for values less than $-0.25 \mathrm{~m} \mathrm{~s}^{-1}$ day $^{-1}$ (light), and greater than $0.25 \mathrm{~m} \mathrm{~s}^{-1}$ day $^{-1}$ (dark). The E-P flux vectors are scaled by the inverse of density to make stratospheric fluxes visible. intraseasonal time scales, while in the latter upward wave propagation is shut off, and wave activity propagates equatorward in concert with the poleward shift of the tropospheric jet.

Corti et al. (1999) propose that it may be possible to interpret climate change as a shift in the frequency of atmospheric circulation regimes. An abrupt transition in climatology can occur when the relative probability of being in the different regime states changes rapidly. Analysis of individual integrations suggests that this is the case in our model. Figure 12 shows the probability density function of the latitude of maximum $850-\mathrm{hPa}$ winds for four different T85 integrations. The presentday and warm world climatological probability density functions are shown in Figs. 12a,d, corresponding to integrations near the ends of the parameter space investigated in our study. In the latter (Fig. 12d) the surface winds are always clustered about $45^{\circ} \mathrm{N}$, while in the former (Fig. 12a) the surface jet resides almost exclusively near $30^{\circ} \mathrm{N}$, sampling higher latitudes with very low probability. In between (Figs. 12b,c), the probability density functions are clearly bimodal: the atmosphere samples both states at different times, the relative weighting shifting in response to the warming.

We explore the vertical structure associated with these two jet states and their relation to climate change in Fig. 13. We characterize the flow as being in a "lowlatitude jet" or "high-latitude jet" state when the 850$\mathrm{hPa}$ wind maximum is equatorward or poleward of $36^{\circ} \mathrm{N}$, the threshold suggested by the minimum in the jet latitude histograms in Fig. 12. The difference between composites of these two states, based on the $\Delta \bar{T}_{p}=5 \mathrm{~K}$ integration, is shown in Fig. 13a. Associated with the shift in the surface winds is a barotropic response throughout the troposphere and a strengthening of the stratospheric polar vortex.

We compare this difference between states with the response to warming in Fig. 13b, which shows the difference between the $\Delta \bar{T}_{p}=5 \mathrm{~K}$ and $7 \mathrm{~K}$ integrations. The similarity between the two supports the conclusion that the abrupt climate transition can be interpreted as a change in the frequency of states. In the $\Delta \bar{T}_{p}=5 \mathrm{~K}$ integration, the circulation favors the low latitude state to high latitude state by a ratio of 7:3. With increased warming in the $\Delta \bar{T}_{p}=7 \mathrm{~K}$ integration, the ratio shifts to $4: 6$.

Further inspection of Fig. 12 suggests that the two atmospheric regimes themselves are not static. For instance, the low-latitude cluster in Figs. 12a-c shifts poleward, beginning equatorward of $30^{\circ} \mathrm{N}$ and ending near $32^{\circ} \mathrm{N}$. This slow shift reflects the smooth, linear response of the tropical temperature structure to heating, which pushes the location of the Hadley cell boundary poleward. The same poleward migration can be observed 
(a) REF

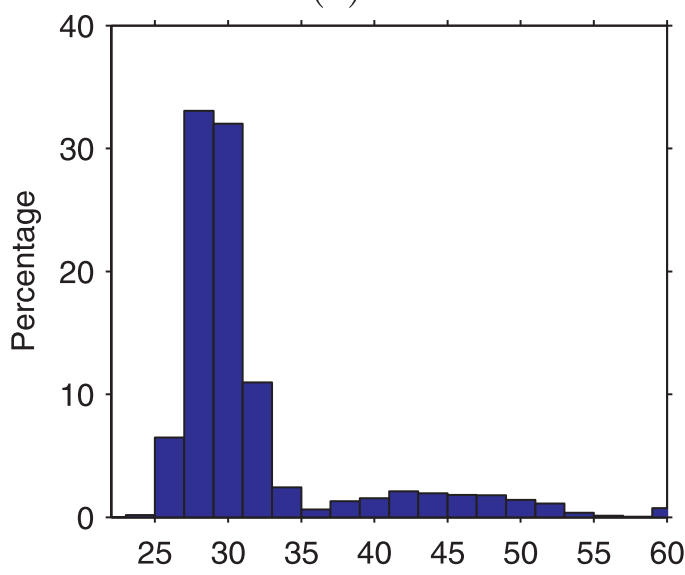

(c) $\Delta \overline{T_{p}}=7 \mathrm{~K}$

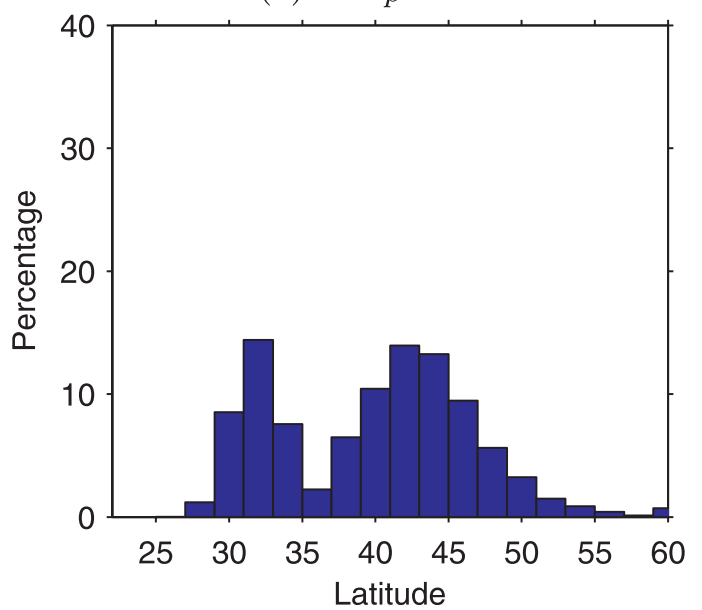

(b) $\Delta \overline{T_{p}}=5 \mathrm{~K}$

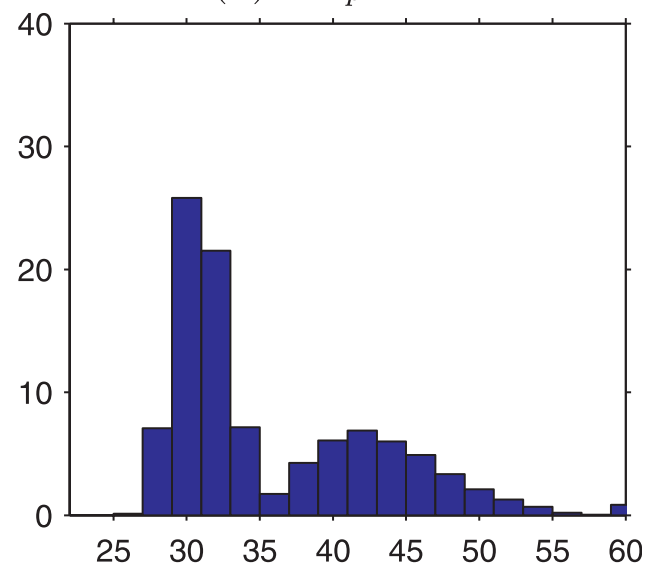

(d) $\Delta \overline{T_{p}}=13 \mathrm{~K}$

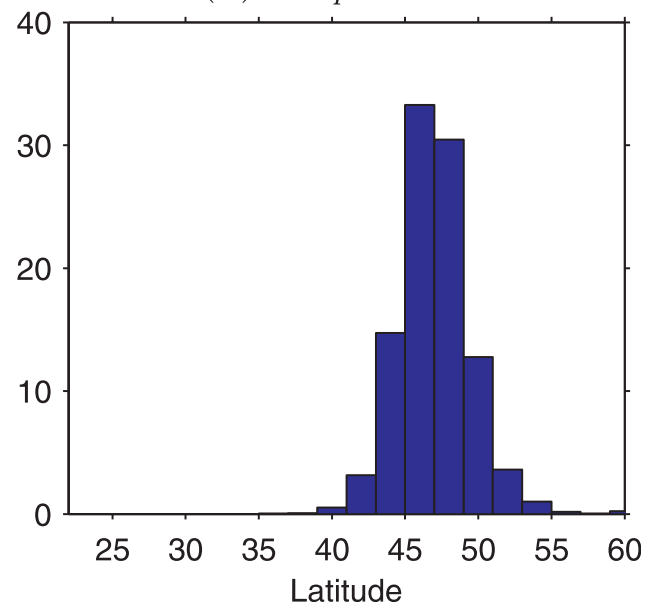

FIG. 12. Histograms of the daily latitude of the maximum wind at $850 \mathrm{hPa}$ for four T85 integrations with $\Delta \overline{T_{p}}=0,5$, 7 , and $13 \mathrm{~K}$. The histograms have been normalized to show the probability of finding the instantaneous jet within each latitude band. Note both the change in the partition of the flow between the low- and high-latitude regimes-the mechanism behind the abrupt climate change-and the gradual shift of the regimes themselves — a reflection of a more linear shift in underlying climatology.

with the high-latitude state: the maximum shifts from approximately $42^{\circ}$ to $46^{\circ}$ between Figs. 12b-d. The change in the frequency of each regime is a nonlinear transition on top of this slow, more predictable response to GHG-induced warming.

The bimodal distribution of jet states near the nonlinear transition is particularly pronounced in the highresolution T85 integrations, some exhibiting a high frequency of SSWs. The anomalous behavior near the regime transition boundary, especially in the T85 integrations, can be diagnosed by analyzing time scales of the atmospheric circulation. We examine the persistence of the annular mode variability, quantified by the $e$-folding time scale $\tau$ of the annular mode autocorrelation function. The autocorrelation time scale quantifies the persistence of intraseasonal variability. Following Gerber et al. (2008), $\tau$ is estimated by fitting the annular mode autocorrelation function to $\exp (-t / \tau)$ in the sense of least squares. We plot $\tau$ at $100 \mathrm{hPa}$ in Fig. 14. This level is chosen because the time scale exhibits a maximum value in the lower stratosphere in nearly all integrations, as well as in observations (Baldwin et al. 2003). Here $\tau$ varies between roughly 30 and 40 days in integrations away from the regime transition boundary, which is approximately comparable to observations, but reaches exceedingly high values in between. The increased autocorrelation time scale near a regime transition is also a common characteristic of general dynamical systems approaching critical transition (Scheffer et al. 2009). 
(a) $\Delta U$ between the high- and low- latitude state

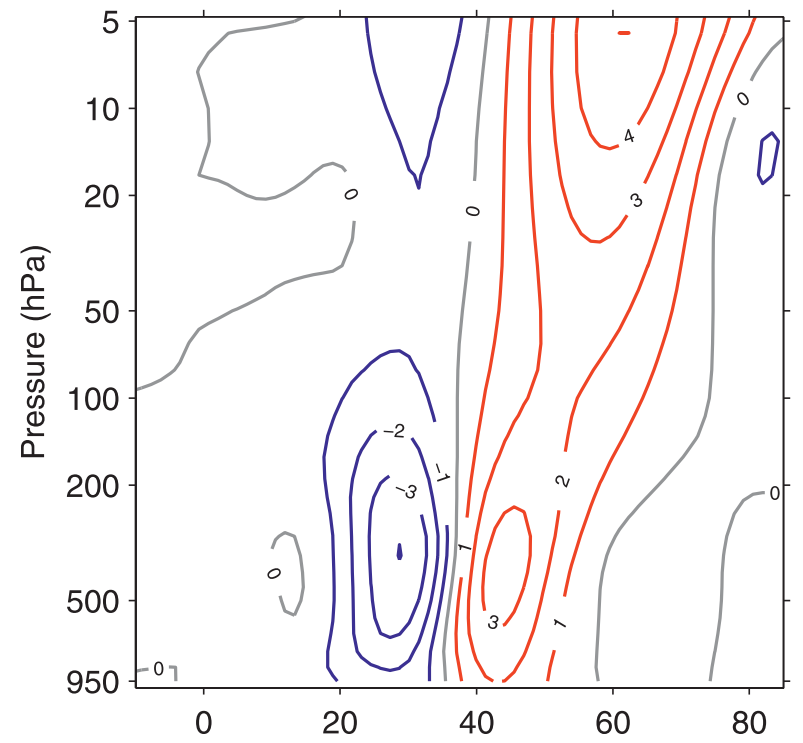

(b) $\Delta \mathrm{U}$ between $\Delta \mathrm{T}_{\mathrm{p}}=5 \mathrm{~K}$ and $7 \mathrm{~K}$

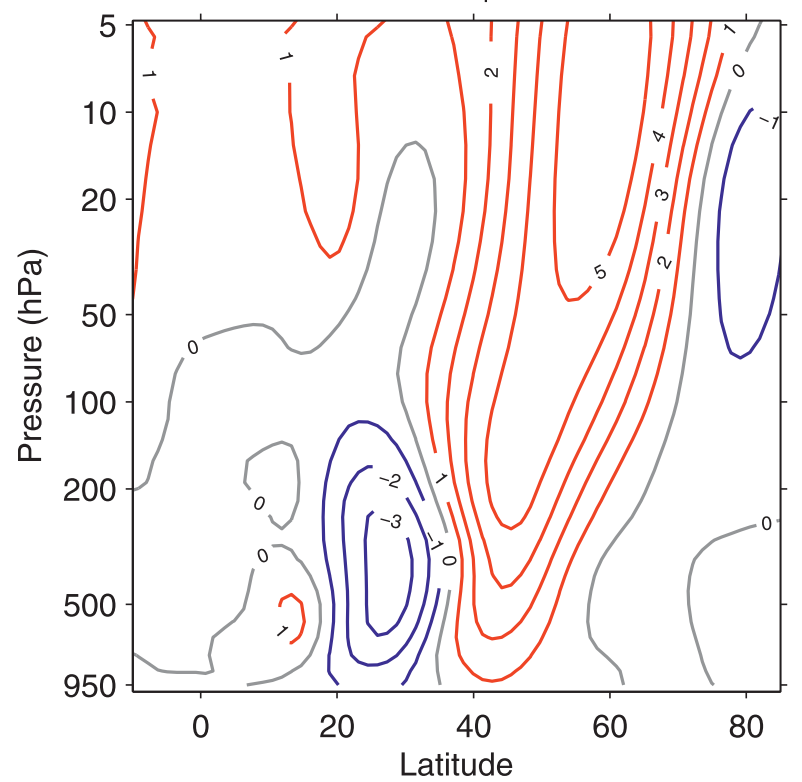

FIG. 13. The connection between flow regimes and the response to warming. (a) The difference between composites of the zonal mean zonal wind based on high-latitude and low-latitude jet states in the T85 integration with $\Delta \overline{T_{p}}=5 \mathrm{~K}$. The flow is characterized as being in the high (low) state when the $850-\mathrm{hPa}$ zonal wind maximum is poleward (equatorward) of $36^{\circ} \mathrm{N}$. (b) The change in the time and zonal mean zonal winds between the T85 integrations with $\Delta \overline{T_{p}}=7$ and $5 \mathrm{~K}$.

These large values of $\tau$ reflect the persistence of the atmospheric state in the alternating regimes. The model will be in one state for a long period before jumping to the other state. Such intermittent behavior has also been observed in models with simplified geometry, such as

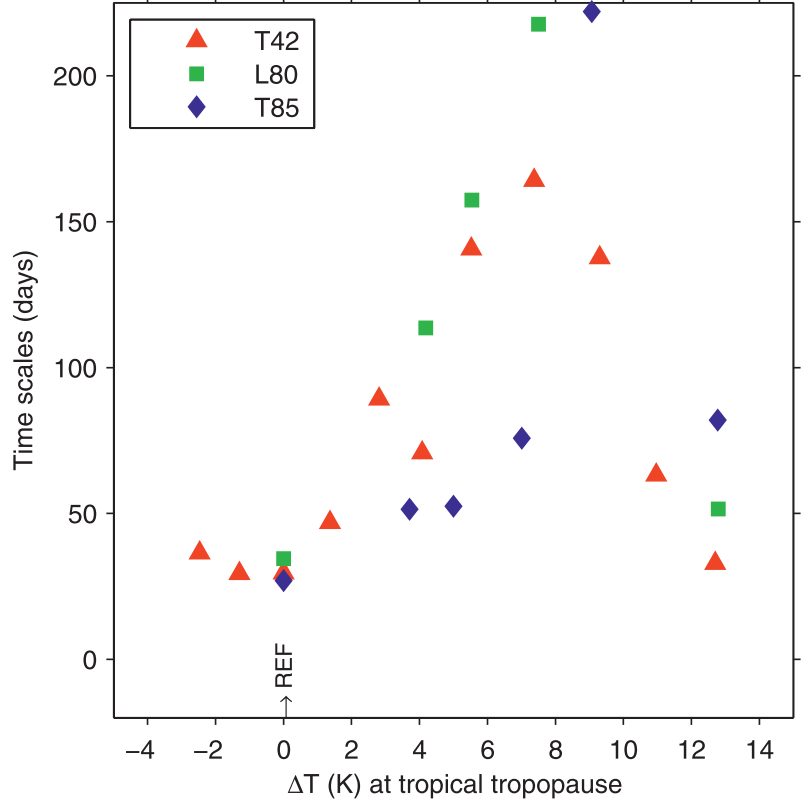

FIG. 14. The $e$-folding time scale $\tau$ of the annular mode autocorrelation function at $100 \mathrm{hPa}$ as a function of tropical warming.

$\beta$-plane models (Lee 1997) and idealized AGCMs (Lee and Kim 2003; Son and Lee 2005; Chan and Plumb 2009). Time series with such regime transitions are not well characterized by an $e$-folding time scale, and often exhibit power-law behavior. Hence, the rule of thumb proposed by Gerber et al. (2008) regarding the integration length needed to accurately estimate the time scale does not apply; extremely long integrations will be needed to effectively compute the climatology and variability, as investigated by Simpson et al. (2010).

While only limited observational evidence for such extreme bimodality is available in observations, Woollings et al. (2010) have found hints that the observed eddydriven jet does show regimelike behavior in the North Atlantic region. This region is dominated by the eddydriven jet and is perhaps a close analog to the rapid shifts in eddy momentum convergence found in our idealized GCM.

\section{Robustness}

We have shown that the underlying regime behavior of our GCM is responsible for the abrupt climate transition. To ensure that this is not an artifact of our particular model numerics or configuration, we perform two additional sets of integrations. In the first set, we keep the forcing exactly the same but radically change the model numerics, replacing the pseudospectral dynamical core with a finite-volume core built on a cubed-sphere grid. This new finite-volume core was constructed for the 
a) latitude of $U_{\max }$ at $850 \mathrm{hPa}$

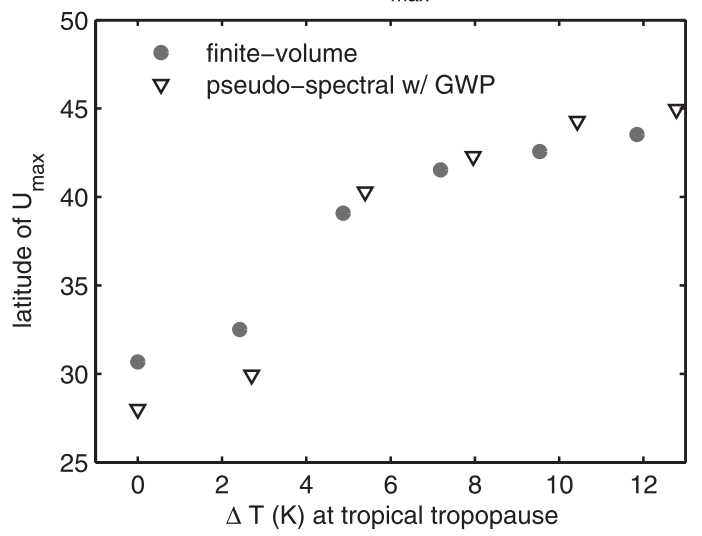

b) $U_{\max }$ at $850 \mathrm{hPa}$

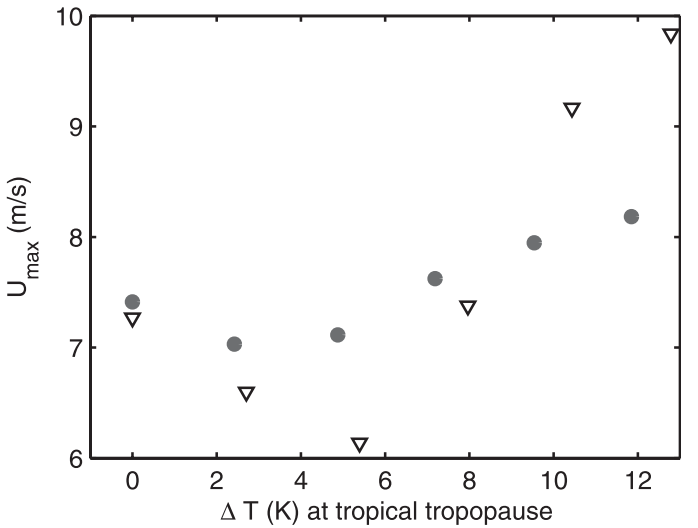

FIG. 15. The (a) position and (b) amplitude of the 850-hPa zonal mean zonal wind maximum as a function of tropical tropospheric warming $\Delta \bar{T}_{p}$ in two alternate models. Both models exhibit an abrupt shift in the eddy-driven jet when the warming exceeds $\sim 5 \mathrm{~K}$, accompanied by a change in the intensity trend. The gray circles show results from integrations of a dynamical core with finite-volume numerics on a cubed-sphere grid; the triangles show results from integrations with the pseudospectral model with a spectral gravity wave parameterization. These figures can be compared to the original pseudospectral model integrations shown in Fig. 6 (top).

GFDL Atmospheric Model, version 3 (AM3), the atmospheric component of their latest coupled climate model, and is described by Donner et al. (2011). The integrations are performed at "C48" resolution, where each side of the cube is a $48 \times 48$ mesh. This resolution was chosen to be fairly comparable to T42, providing roughly four grid points to resolve wavenumber 42 . The core employs a hybrid coordinate in the vertical, and we specify the same 40 levels as in our L40 integrations with the pseudospectral model.

The second set of integrations is designed to ensure that our results are not an artifact of the crude treatment of mesospheric gravity wave drag in the Polvani and Kushner (2002) forcing. Shepherd and Shaw (2004) and Shaw et al. (2009) document that an improper treatment of gravity waves in the stratosphere can distort tropospheric circulation through downward control. A concern is that Rayleigh friction does not respect the conservation of momentum, so we retain the original T42L40 pseudospectral dynamical core but replace the Rayleigh friction with the spectral gravity wave parameterization developed by Alexander and Dunkerton (1999). The scheme assumes a broad spectrum source of gravity waves, and we adopt the settings used in GFDL AM3 (Donner et al. 2011), with the exception that we reduce the amplitude in the deep tropics by $90 \%$ (this prevents the formation of spurious jets in the tropical stratosphere, though we find that all of the results are similar if we keep the exact AM3 settings). To ensure the conservation of momentum, any remaining wave flux that reaches the upper boundary of the model is deposited in the uppermost model level, as suggested by Shaw et al. (2009). As the spectral gravity wave scheme produces significant damping in the lower stratosphere, we obtain a more comparable climatology by increasing the equilibrium lapse rate parameter $\gamma$ to $6 \mathrm{~K} \mathrm{~km}^{-1}$.

Figure 15 summarizes the results from six integrations with each model, in which the heating parameter $H_{0}$ was varied linearly from 0 (reference) to $0.5 \mathrm{~K} \mathrm{day}^{-1}$. Statistics are based on 10000 days of integration after a 300-day spinup period. Since the tropical warming scales linearly with the heating, results are reported as a function of warming at the tropical tropopause $\left(\Delta \overline{T_{p}}\right)$, as in previous sections. In both models the surface wind maximum jumps poleward when the warming exceeds approximately $5 \mathrm{~K}$, consistent with the behavior observed in our original model configuration. The surface wind trends also change nonlinearly, initially decreasing with additional warming but increasing after the regime transition. The nonlinearity, both in the intensity and position, however, is weaker in the finite-volume core.

The difference between the two models, and the connection between the jet position and strength, can be understood in terms of combinations of the two jet states. Figure 16 shows the time mean, zonal mean 850-hPa winds for the 12 integrations. In the present-day state $\left(\Delta \bar{T}_{p}=0\right)$, the jet is strongest near $30^{\circ} \mathrm{N}$ in both models. It also exhibits a shoulder at $\sim 45^{\circ} \mathrm{N}$ that grows with increased warming, becoming the dominant jet in the warm world climatologies. Rapid changes occur when the latter state begins to dominate the former at a warming of about $\Delta \bar{T}_{p}=5 \mathrm{~K}$. At this time the jet is substantially weaker but broader, reflecting the average of the two states. The initial and final jet states, however, 

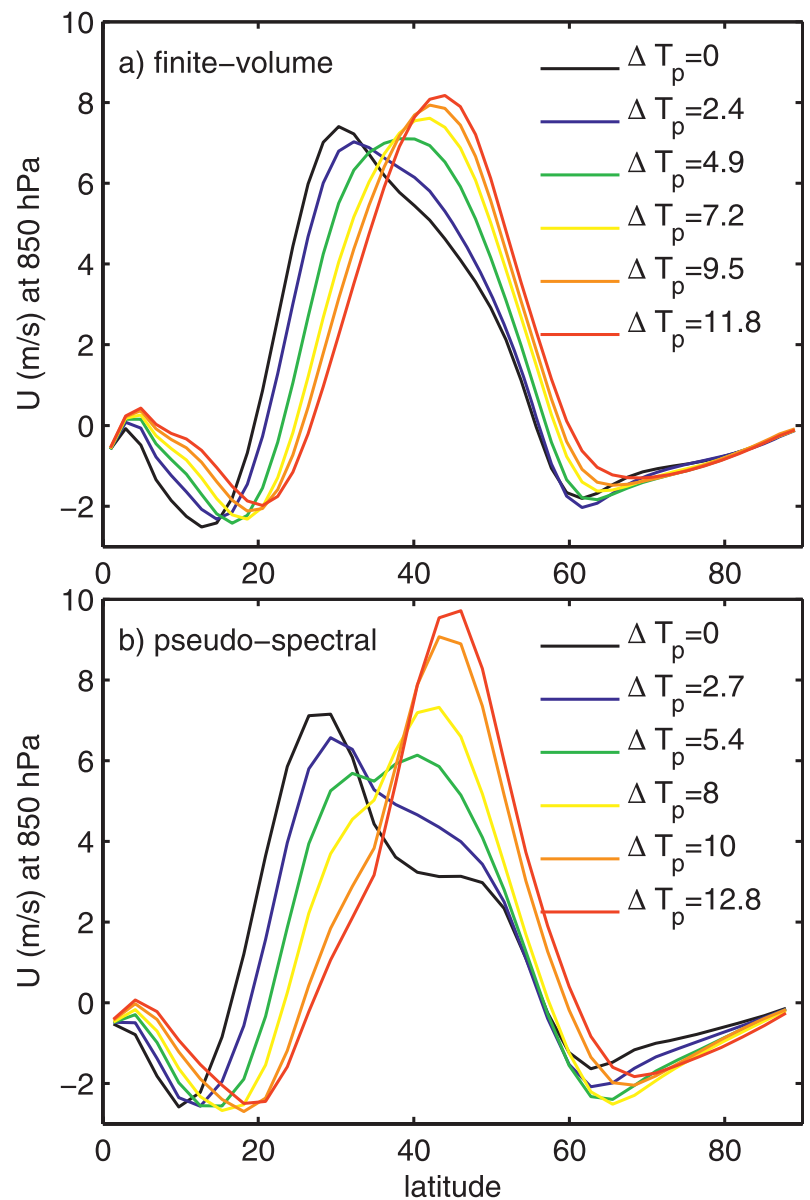

FIG. 16. The zonal mean zonal wind at $850 \mathrm{hPa}$ as a function of latitude for the integrations summarized in Fig. 15: $\Delta \bar{T}_{p}$ denotes the warming of tropical tropopause. In both models the nonlinear response to warming reflects a transition from a state with surface winds centered near $30^{\circ} \mathrm{N}$ (e.g., for the reference $\Delta \bar{T}_{p}=0$ integrations) to one with winds centered near $45^{\circ}$ (integrations with $\left.\Delta \bar{T}_{p}>8 \mathrm{~K}\right)$. In between, especially for $\Delta \bar{T}_{p} \approx 5$, the mean jet becomes much broader because the model samples both states, as suggested in Fig. 12. The "present day" and "warm world" states are more distinct in the spectral model, making the transition more abrupt relative to the finite-volume model.

are less distinct in the finite-volume model. Thus, the transition is less abrupt.

While we have focused on the surface winds here, the vertical structure of the response outlined in sections 4 and 5 is robust for these two alternate models. The surface winds owe their existence to eddy momentum flux convergence in the upper atmosphere and, hence, provide a good measure of the eddy-driven circulation throughout the troposphere. Both the finite-volume cubed-sphere dynamical core and the use of spectral gravity wave drag parameterizations in idealized models are the subject of ongoing research. The results shown in this paper are preliminary and are shown chiefly to establish the robustness of the abrupt circulation change found with the original version of the model.

\section{Conclusions}

We have explored changes in the general circulation of the atmosphere and the coupling between the stratosphere and troposphere under climate change-like thermal forcing with an idealized AGCM. The thermal forcing was imposed in the low-latitude upper troposphere, as in Butler et al. (2010), to mimic the enhanced warming there caused by increased GHG concentrations. In this study we focused on the sensitivity of the response to the amplitude of the warming, exploring a range of warming comparable in magnitude to that anticipated by comprehensive climate models under the A1B and A2 emission scenarios. We found that the eddy-driven circulation responds to the warming in a highly nonlinear fashion, exhibiting an abrupt climate shift when the tropical warming exceeds a critical amplitude.

In the troposphere warming of the tropics causes expansion and weakening of the Hadley cells and poleward displacement of the extratropical jet streams, as reported in Butler et al. (2010). For the midlatitude and stratosphere circulation, however, the response is a highly nonlinear function of the forcing amplitude. The near-surface jet exhibits an abrupt $10^{\circ}$ shift toward high latitudes when the tropical warming exceeds $5 \mathrm{~K}$. While the poleward migration of the upper-level westerly jet is smoother, the trends in wind strength at lower and upper levels exhibit a marked shift at the transition point, further suggesting that the change is due to a reorganization of the eddy-driven circulation. For weak to moderate warming, the trend in wind strength is small or negative; after the critical threshold, the winds accelerate with additional warming. In the stratosphere the polar vortex expands equatorward and strengthens with moderate warming in the tropics but, as with the tropospheric jet, the trends change abruptly with increased warming. This regime shift can be understood as an abrupt rearrangement of planetary and synoptic-scale waves in the upper troposphere and lower stratosphere, altering the eddy transport of momentum and heat.

As the stratospheric circulation is largely driven by wave-mean flow interactions, the regime shift is magnified there. For weak to moderate warming, the BrewerDobson circulation (BDC) increases moderately. After the critical threshold, stratosphere-troposphere coupling on intraseasonal time scales collapses as wave activity, which formerly entered the stratosphere, is steered away. The presence of regimes may help resolve the seemingly contrasting results in the idealized modeling studies of Eichelberger and Hartmann (2005) and Butler et al. 
(2010), who found responses of the BDC to tropical warming of opposite sign.

The idealized nature of the forcing in our model allows us to test the robustness of the circulation changes to numerical truncation, model numerics, and our treatment of gravity wave drag, experiments not easily accomplished with a comprehensive GCM with resolution-dependent parameterizations. We verified that all essential aspects of the circulation changes are robust. The exact location of the critical threshold, however, does appear to be sensitive to numerical truncation and is pushed back to higher warming levels in higher-resolution integrations. The abruptness of the change is also sensitive to the numerics of the model.

As shown by Butler et al. (2010), the circulation response of the idealized model to the warming of the tropical upper troposphere captures much of the total circulation change projected by comprehensive models. This indicates that the dynamical response of the atmosphere to GHG forcing is dominated by changes in temperature gradients. The stratospheric response is particularly noteworthy here, as one might expect direct GHG-induced cooling and ozone recovery to play a critical role as well.

It is important to keep in mind that the quantitative position of the abrupt transition in our integrations should not be taken too literally due to the gross simplification of the physics in our model. Rather, the key result of our study is the existence of dynamical regimes and abrupt transitions in models with fully resolved dynamics. In this respect, our results complement previous studies with EMICs, which document the potential for abrupt climate change due to nonlinear feedback with climate forcings. Our idealized forcing is extremely smooth, as seen from the direct response of the tropical, thermally driven circulation in the model. Ice albedo, water vapor, and ozone chemistry feedbacks are completely absent in these integrations. Despite this, the large-scale dynamics alone are able to induce abrupt reorganization of the wave-mean flow interactions, leading to rapid changes in the climatology and variability of the atmosphere. A complete transition from one regime to another is possible over a range of warming comparable in magnitude to that found in twenty-first century climate projections. Whether such dynamical regimes are observable in the atmosphere remains an open question.

Acknowledgments. This work was supported in part by grants from the National Science Foundation awarded to Columbia University and New York University. We thank the NCAR Computational and Information Systems Laboratory and New York University High Performance Computing Center, where integrations were performed, and three anonymous reviewers for their comments on an earlier version of the manuscript.

\section{REFERENCES}

Alexander, M. J., and T. J. Dunkerton, 1999: A spectral parameterization of mean-flow forcing due to breaking gravity waves. J. Atmos. Sci., 56, 4167-4182.

Alley, R. B., 2007: Wally was right: Predictive ability of the North Atlantic "Conveyor belt" hypothesis for abrupt climate change. Annu. Rev. Earth Planet. Sci., 35, 241-272.

Andrews, D. G., J. R. Holton, and C. B. Leovy, 1987: Middle Atmosphere Dynamics. Academic Press, Inc., 489 pp.

Baldwin, M. P., 2003: Comment on "Tropospheric response to stratospheric perturbations in a relatively simple general circulation model" by Lorenzo M. Polvani and Paul J. Kushner. Geophys. Res. Lett., 30, 1812, doi:10.1029/2003GL017793.

— D. B. Stephenson, D. W. J. Thompson, T. J. Dunkerton, A. J. Charlton, and A. O. Neill, 2003: Stratospheric memory and skill of extended-range weather forecasts. Science, 301, 636-640.

Butchart, N., and Coauthors, 2006: Simulations of anthropogenic change in the strength of the Brewer-Dobson circulation. Climate Dyn., 27, 727-741, doi:10.1007/s00382-006-0162-4.

_ , and Coauthors, 2010: Chemistry-climate model simulations of twenty-first century stratospheric climate and circulation changes. J. Climate, 23, 5349-5374.

Butler, A. H., D. W. J. Thompson, and R. Heikes, 2010: The steadystate atmospheric circulation response to climate change-like thermal forcings in a simple general circulation model. $\mathrm{J}$. Climate, 23, 3474-3496.

Chan, C. J., and R. A. Plumb, 2009: The response to stratospheric forcing and its dependence on the state of the troposphere. J. Atmos. Sci., 66, 2107-2115.

Charlton-Perez, A., L. Polvani, J. Austin, and F. Li, 2008: The frequency and dynamics of stratospheric sudden warmings in the 21st century. J. Geophys. Res., 113, D16116, doi:10.1029/ 2007JD009571.

Claussen, M., and Coauthors, 2002: Earth system models of intermediate complexity: Closing the gap in the spectrum of climate system models. Climate Dyn., 18, 579-586, doi:10.1007/ s00382-001-0200-1.

Clement, A. C., and L. C. Peterson, 2008: Mechanisms of abrupt climate change of the last glacial period. Rev. Geophys., 46, RG4002, doi:10.1029/2006RG000204.

Corti, S., F. Molteni, and T. N. Palmer, 1999: Signature of recent climate changes in frequencies of natural atmospheric regimes. Nature, 398, 799-802.

Donner, L. J., and Coauthors, 2011: The dynamical core, physical parameterizations, and basic simulation characteristics of the atmospheric component AM3 of the GFDL global coupled model CM3. J. Climate, 24, 3484-3519.

Edmon, H. J., B. J. Hoskins, and M. E. McIntyre, 1980: EliassenPalm cross sections for the troposphere. J. Atmos. Sci., 37, 2600-2616.

Eichelberger, S. J., and D. L. Hartmann, 2005: Changes in the strength of the Brewer-Dobson circulation in a simple AGCM. Geophys. Res. Lett., 32, L15807, doi:10.1029/2005GL022924.

Engel, A., and Coauthors, 2009: Age of stratospheric air unchanged within uncertainties over the past 30 years. Nat. Geosci., 2, 28-31.

Frierson, D. M. W., J. Lu, and G. Chen, 2007: Width of the Hadley cell in simple and comprehensive general circulation models. Geophys. Res. Lett., 34, L18804, doi:10.1029/2007GL031115. 
Ganopolski, A., and S. Rahmstorf, 2001: Rapid changes of glacial climate simulated in a coupled climate model. Nature, 409, 153-158.

Garcia, R. R., W. J. Randel, and E. E. Kinnison, 2011: On the determination of age of air trends from atmospheric trace species. J. Atmos. Sci., 68, 139-154.

Gerber, E. P., and L. M. Polvani, 2009: Stratosphere-troposphere coupling in a relatively simple AGCM: The importance of stratospheric variability. J. Climate, 22, 1920-1933.

_ - S. Voronin, and L. Polvani, 2008: Testing the annular mode autocorrelation time scale in simple atmospheric general circulation models. Mon. Wea. Rev., 136, 1523-1536.

- C. Orbe, and L. M. Polvani, 2009: Stratospheric influence on the tropospheric circulation revealed by idealized ensemble forecasts. Geophys. Res. Lett., 36, L24801, doi:10.1029/ 2009GL040913.

Haynes, P. H., C. J. Marks, M. E. McIntyre, T. G. Shepherd, and K. P. Shine, 1991: On the "downward control" of extratropical diabatic circulations by eddy-induced mean zonal forces. J. Atmos. Sci., 48, 651-679.

Held, I. M., 2000: The general circulation of the atmosphere. Proc. 2000 Program in Geophysical Fluid Dynamics, Woods Hole, MA, Woods Hole Oceanographic Institute, 1-54.

__ and A. Hou, 1980: Nonlinear axially symmetric circulations in a nearly inviscid atmosphere. J. Atmos. Sci., 37, 515-533.

— , and M. J. Suarez, 1994: A proposal for the intercomparison of the dynamical cores of atmospheric general circulation models. Bull. Amer. Meteor. Soc., 75, 1825-1830.

$\mathrm{Hu}$, Y., and Q. Fu, 2007: Observed poleward explasion of the Hadley circulation since 1979. Atmos. Chem. Phys., 7, 5229-5236.

Hurwitz, M. M., P. A. Newman, and C. I. Garfinkel, 2011: The Arctic vortex in March 2011: A dynamical perspective. Atmos. Chem. Phys. Discuss., 11, 22 113-22 127, doi:10.5194/acpd-1122113-2011.

Lee, S., 1997: Maintenance of multiple jets in a baroclinic flow. J. Atmos. Sci., 54, 1726-1738.

- , and H.-k. Kim, 2003: The dynamical relationship between subtropical and eddy-driven jets. J. Atmos. Sci., 60, 1490-1503.

Li, F., J. Austin, and J. Wilson, 2008: The strength of the BrewerDobson circulation in a changing climate: Coupled chemistry climate model simulations. J. Climate, 21, 40-57.

Lu, J., G. Chen, and D. M. W. Frierson, 2008: Response of the zonal mean atmospheric circulation to El Niño versus global warming. J. Climate, 21, 5835-5851.

McLandress, C., and T. G. Shepherd, 2009a: Impact of climate change on stratospheric sudden warmings as simulated by the Canadian middle atmosphere model. J. Climate, 22, 5449-5463. , and $-2009 \mathrm{~b}$ : Simulated anthropogenic changes in the Brewer-Dobson circulation, including its extension to high latitudes. J. Climate, 22, 1516-1540.
Miller, R. L., G. A. Schmidt, and D. T. Shindell, 2006: Forced annular variations in the 20th century Intergovernmental Panel On Climate Change Fourth Assessment Report models. J. Geophys. Res., 111, D18101, doi:10.1029/2005JD006323.

Peixoto, J. P., and A. H. Oort, 1992: Physics of Climate. SpringerVerlag, $520 \mathrm{pp}$.

Polvani, L. M., and P. Kushner, 2002: Tropospheric response to stratospheric perturbations in a relatively simple general circulation model. Geophys. Res. Lett., 29, 1114, doi:10.129/ 2001GL014284.

Scheffer, M., and Coauthors, 2009: Early-warning signals for critical transitions. Nature, 461, 53-59, doi:10.1038/nature08227.

Schneider, T., 2004: The tropopause and the thermal stratification in the extratropics of a dry atmosphere. J. Atmos. Sci., 61, 1317-1340.

— , and C. Walker, 2006: Self-organization of atmospheric macroturbulence into critical states of weak nonlinear eddy-eddy interactions. J. Atmos. Sci., 63, 1569-1586.

Seager, R., and D. S. Battisti, 2006: Challenges to our understanding of the general circulation: Abrupt climate change. The Global Circulation of the Atmosphere, T. Schneider and A. H. Sobel, Eds., Princeton University Press, 331-372.

Seidel, D. J., and W. J. Randel, 2007: Recent widening of the tropical belt: Evidence from tropopause observations. J. Geophys. Res., 112, D20113, doi:10.1029/2007JD008861.

Shaw, T. A., M. Sigmond, T. G. Shepherd, and J. F. Scinocca, 2009: Sensitivity of simulated climate to conservation of momentum in gravity wave drag parameterization. J. Climate, 22, 27262742.

Shepherd, T. G., 2008: Dynamics, stratospheric ozone, and climate change. Atmos.-Ocean, 46, 117-138.

, and T. A. Shaw, 2004: The angular momentum constraint on climate sensitivity and downward influence in the middle atmosphere. J. Atmos. Sci., 61, 2899-2908.

Simpson, I. R., M. Blackburn, J. D. Haigh, and S. N. Sparrow, 2010: The impact of the state of the troposphere on the response to stratospheric heating in a simplified GCM. J. Climate, 23, 61666185 .

Son, S.-W., and S. Lee, 2005: The response of westerly jets to thermal driving in a primitive equation model. J. Atmos. Sci., 62, 3741-3757.

Weber, S. L., 2010: The utility of Earth system Models of Intermediate Complexity (EMICs). WIREs Climate Change, 1, 243-252.

Woollings, T., A. Hannachi, and B. Hoskins, 2010: Variability of the North Atlantic eddy-driven jet stream. Quart. J. Roy. Meteor. Soc., 136, 856-868.

Yin, J. H., 2005: A consistent poleward shift of the storm tracks in simulations of 21 st century climate. Geophys. Res. Lett., 32, L18701, doi:10.1029/2005GL023684. 